Portland State University

PDXScholar

\title{
The process of short-term psychotherapy with mentally deficient adults
}

Joan Emily Carpenter

Portland State University

Follow this and additional works at: https://pdxscholar.library.pdx.edu/open_access_etds

Part of the Psychiatric and Mental Health Commons, and the Psychoanalysis and Psychotherapy Commons

Let us know how access to this document benefits you.

\section{Recommended Citation}

Carpenter, Joan Emily, "The process of short-term psychotherapy with mentally deficient adults" (1980). Dissertations and Theses. Paper 3099.

https://doi.org/10.15760/etd.3093

This Thesis is brought to you for free and open access. It has been accepted for inclusion in Dissertations and Theses by an authorized administrator of PDXScholar. Please contact us if we can make this document more accessible: pdxscholar@pdx.edu. 
AN ABSTRACT OF THE THESIS of Joan Emily Carpenter for the Naster of Science in Psychology presented Nay 15, 1980.

Title: The Frocess of Short-Term Fsychotherapy with Nentally Deficient Adults

AFFROVED BY MENBERS OF THE THESIS CCMMITTEE:

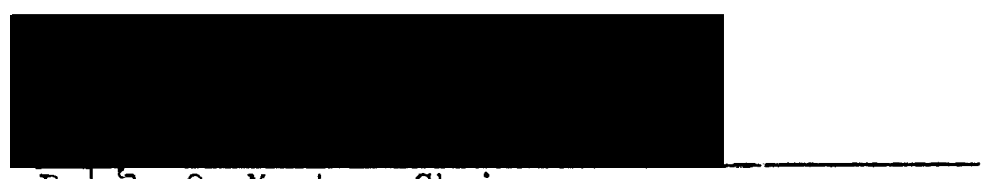

Fanela 0. Munter, Chair

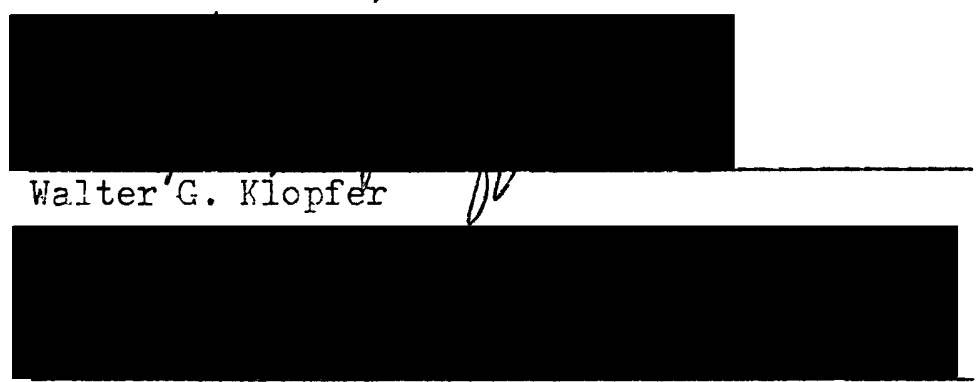

Cathleen I. Smith

This paper explores the process of individual short-term egcsupportive psychotherapy with mentally deficient adults. The Jiterature on clinical research, case studies, process research, short-term psychotherapy, and therapy with the menta].ly retarded is selectively reviewed. Four case studies are presented with clients at the Fortland Habilitation Center, a sheltered workshop which trains mentally deficient adults in socialization, practical Jiving, and job skills. Finally, the case studies are discussed in terms of the selected literature. 
Client-subjects were drawn from a waiting list compiled by staff members, supervisors, teachers, and counselors at the Center. Selectior of subjects was based on perceived need of the client. The number of meetings ranged from 14 to 16 . Sessions were held trice a week for six weeks, then once a week for 3-5 weeks. The duration of individual sessions ranged from 12 to 60 minutes. Most sessions were audio recorded. and typewritten transcripts were prepared from the tapes.

Individual goals and agenda were prepared for each client and were updated continuously as therapy progressed. Traditional and special. therapeutic techniques employed included transference, resistance, free association, increasing client self-esteem, reality testing and assertiveness training.

The study illustrates the step-by-stef method by which the client in therapy moves from a type of impersonal reporting to describing feelings and emotion as part of present experience. The two clients who made the most progress began with this impersonal type of reporting and were able to finally experience, and report that experiencine in the present moment. A third client did not move noticeably through therary but did receive some exposure to the technique of reality checking and acquired some assertiveness skills. The fourth client did not appear to move at all but did develop an increased awareness of his ability to control his environment and became interested in community mobility. The study demonstrates that the process of ego-supportive shortterm therapy results in more verbalization or expression of immediate feelings in some clients, and that all clients benefit in some way from the intimacy of the therapeutic relationship. 
THE PROCESS OF SHORT-TERM PSYCHOTHERAPY

WITH MENTALLY DEFICIENT ADULTS

by

JOAN EMILY CARPENTER

A thesis submitted in partial fulfillment of the requirements for the degree of

\author{
MASTER OF SCIENCE \\ in \\ PSYCHOLOGY
}

Portland State University

1980 
TO THE OFFICE OF GRADUATE STUDIES AND RESEARCH:

The members of the Committee approve the thesis of Joan Emily Carrenter presented Nay 15, 1980.

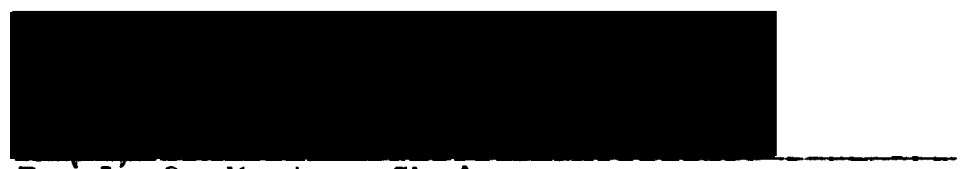

Famela O. Nunter, Chair

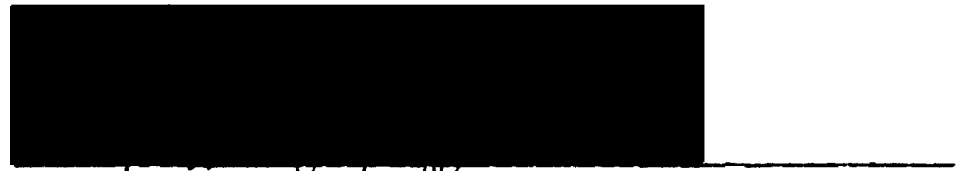

Wa]ter G. Klopfer $J$

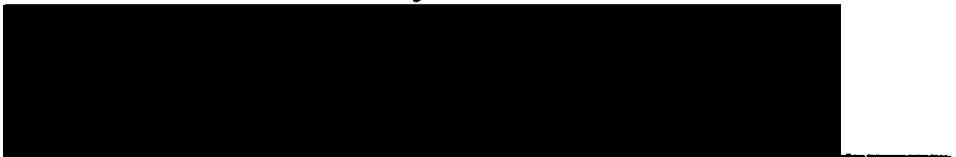

Cathleen I. Smith

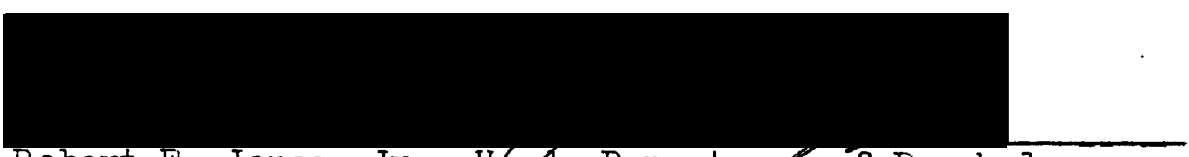

Robert E. Jones, Jr., Head, Department of Psychology

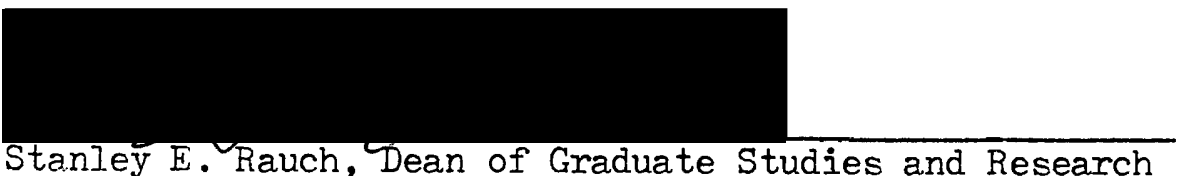


The author wishes to acknowledge the cooperation of the staff and clients at the Portland Habilitation Center who assisted in gathering data for this thesis. special thanks are due the client-subjects who spent many hours participating in this study and who were willing to share a portion of their lives with us.

My sincere appreciation goes to my chairperson, Pamela Munter, who has also been my supervisor, mentor, teacher, and friend. To my colleagues, Pauline wall and Susan Paltrow, go my thanks for their encouragement and assistance. Thanks are also due committee members walter G. Klopfer and Cathleen L. Smith for their excellent advice. To my fellow students who share space in the graduate's lounge may I express my appreciation for many hours of camaraderie and support.

Finally, special thanks are due my friend, Shirley Logan, who provided the emotional support and financial assistance to make possible the completion of this project. 
CHAPTER

clinical research and case studies

Psychotherapy defined

case histories and process research

Process defined

Other case histories

Short-term psychotherapy

Lengthening factors

Short-term therapy defined

Time factors

Selection criteria

Techniques

Psychotherapy with retardates

Mental retardation defined

Mental retardation classified

History

Research

The case of Marian

The case of Richard

The case of Cathy

The case of Ray

Transference 


\section{Introduction}

The purpose of this paper is to explore the process of individual short-term psychotherapy with mentally deficient adults. The literature on clinical research, case studies, process research, short-term psychotherapy, and therapy with the mentally retarded is selectively reviewed. Case studies are presented with clients at the Portland Habilitation Center. Finally, the case studies are discussed in terms of the selected literature.

Recent trends in the field of mental retardation have generated a number of programs designed to integrate retarded children and adults as much as possible into the community at large. "Guided by a 'principle of normalization' which holds that mentally retarded citizens are entitled to services which are 'as culturally normative as possible'... various forms of community placement are being substituted for institutional care" (Robinson and Robinson, 1976, pg. 47). Among these are regular classes, group homes, sheltered workshops and vocational training. Public Law 94-192 emphasizes the government's commitment to provide free and appropriate public education to all handicapped children. This law requires individualized planning for the education of all handicapped boys and girls. The civil rights of retarded citizens are further protected in Oregon by Public Law \#659.405, amended by the 1973 legislature, which prohibits 
discrimination of physically and mentally handicapped persons in the areas of employment, public accommodation, resort or amusement, and housing.

While the emphasis on normalization has done much to improve the services offered to retarded citizens, there is little being done to provide psychotherapy to these individuals. Early practitioners relied on the theories of popular figures like Freud (1904) and Rogers' (1951) who concluded that psychotherapy with retardates was impossible because of their lack of insight, verbal ability and normal intelligence (Robinson and Robinson, 1976). Yet a few early researchers claimed success (AbeI and Kinder, 1953; Ackerman and Menninger, 1936; Chidester and Menninger, 1934; Thorne, 1948) and generated the classic volumes that have been written since (Baumeister, 1967; Clarke and Clarke, 1974, El1is, 1966; Robinson and Robinson, 1976; Stacey and DeMartine, 1957). The most highly developed approaches reported in the literature are based on behavior modification techniques, but it has been suggested that other approaches may also be feasible (Robinson and Robinson, 1976).

For the purpose of this study, mental retardation is defined as "significantly subaverage general intellectual functioning existing concurrently with deficits in adaptive behavior, and manifested during the developmental period" according to the 1973 American Association of Mental Deficiency (AAMD) revised Manual on Terminology and Classification. Intellectual functioning is usually measured by one 
of the standardized tests such as the Wechsler or the Stanford-Binet. A significantly subaverage performance on one of these tests would be indicated by a score which is more than two standard deviations below the mean or average. This represents a score of 69 on the Wechsler and 67 on the Stanford-Binet (Robinson and Robinson, 1976, pg. 30).

The study was conducted at the Portland Habilitation Center, 3829 S.E. 74 th Avenue, Portland, Oregon. Permission was granted by Robert Stuva, Executive Administrator. The Portland Habilitation Center is a sheltered workshop which trains mentally deficient adults in socialization, practical living, and job skills. A social behaviors program operationally defines problem behaviors, and individual remedies are implemented for their correction. In addition, the Center provides testing, assessment, group therapy, and individual psychotherapy. 1

In contrast to the program at the Portland Habilitation Center, which is based on operant learning techniques to eliminate problem behaviors, the present study was designed to provide individual psychotherapy to selected clients.

Client-subjects were drawn from a waiting list compiled by staff members, supervisors, teachers, and counselors at

${ }^{1}$ Under the supervision of Dr. Pamela 0 . Munter, Clinical. Psychologist and Portland State University Associate Professor in Psychology. 
the Center. Selection of subjects was based on perceived need of the client. Prospective clients were individually interviewed. During the interview the project was explained, the consent agreement was read with each subject, and his or her questions were answered. Informed consent was received from each participant. Six client subjects were selected for the study. Four of the subjects completed the sessions. One subject voluntarily withdrew from participation because of his own lack of interest in the project. The sixth subject was excluded from the report because of excessive absenteeism, but he continued to work with the therapist whenever he felt the need to talk.

The number of meetings ranged from 14 to 16 . The sessions were held twice a week for six weeks (with one absence by each client due to severe weather conditions), then once a week for three, four, or five weeks. The duration of the individual sessions ranged from 12 minutes to 60 minutes.

Most sessions were audio recorded and typewritten transcripts were prepared from the tapes. Information on non-verbal and other pertinent behaviors were carefully noted and recorded. Complete records were kept only by the therapist. A brief set of notes was submitted to the director at the Center and kept in the client's confidential file. Clients are identified by the first names only, to protect anonymity. Since all client subjects in this study 
have ordinary first names, confidentiality was protected.

Individual goals and agenda were prepared for each client based on his or her presenting problems and will be discussed in detail in the case studies for each client. The agenda were updated continuously as the therapy progressed under the supervision of $\mathrm{Dr}$. Munter. Traditional and special therapeutic techniques employed included transference (the broad definition), resistance, interpretation, free association, increasing client self-esteem, reality testing, reassurance, support, counseling and guidance (advice), reflection and clarification of feelings, alternative guidance, directed discussion, projective techniques, assertive training, social work and advocacy.

During the process of individual short-term psychotherapy, the client is led from an impersonal type of psychological functioning to a level of immediate experiencing of personal feelings which are felt as owned and accepted. Since the focus of interest is the process, no measures of outcome were used. Indeed, in a study of process, outcome measures are considered inappropriate (Kiesler, 1973). By examining this process the case studies show that adult retardates can use this process for grasping concrete insights about their own behavior, and that they can experience, own and accept feelings, and express emotion in the present. 


\section{Review of the Literature}

This chapter reviews the literature on the process of short-term psychotherapy with mentally deficient adults by establishing definitions and guidelines on the process nature of therapy, on short-term therapy, and on therapy with the mentally retarded. The review further establishes that case studies are a respected method of clinical reporting.

\section{Clinical Research and Case Studies}

The origins of clinical psychology are found in the psychometric and dynamic traditions in psychology. Psychometrics began with the investigation of individual differences through the development of mental tests, and gained impetus through the need for large scale testing of recruits in World War I. The dynamic tradition was founded in a concern with pathology and the search for an explanation of mental disturbances in disease processes. Interest in psychotherapy stimulated G. Stanley Hall to invite Freud and Jung to visit the United States, thus generating support for psychoanalysis in this country. The number of clinical psychologists practicing therapy gradually increased during the twenties and thirties, and the work of Carl Rogers finally reached national prominance in the forties (Watson, $1953)$.

Psychotherapy defined. Many attempts have been made over the years to define psychotherapy and to describe 
activities which may have therapeutic or curative effects. In its strictest sense the term refers to the techniques that are used by the specialist but, according to Chaplin's (1975) Dictionary of psychology, it can be used more loosely to include informal talks or personal discussions with ministers, teachers, or friends.

Weiner (1976) clarified the use of the term in his discussion of individual psychotherapy. He described a recent attempt by Reisman (1971) to integrate a number of definitions into a few broad categories. Reisman found that the 31 definitions could be classified into four types: psychotherapy defined by (1) its goals, (2) its procedures, (3) its practitioners or (4) the relationship. While none of these classifications was adequate by itself, the characteristics they held in common led to a definition of psychotherapy as "the communication of person-related understanding, respect, and a wish to be of help." This definition of psychotherapy might lead to the belief that it can occur in many types of interpersonal relationships, but Weiner states that it is most likely to occur if one of the two people in the relationship is a trained professional and if the relationship exists primarily for the benefit of the patient. The professional relationship, moreover, is arranged in a systematic fashion over a specified length of time and "continues as long as it serves the needs of the patient," but "unlike other kinds of interpersonal relationships, it 
is not broken off during transient periods of waning enthusiasm." (pg. 333-335).

Leland and Smith (1974, pg. 198), researchers in the field of mental retardation, define psychotherapy as "any planned or goal-directed attempt to create behavioral change in persons, regardless of the materials or procedures used, but must include a close interpersonal relationship between persons and therapist, an organized treatment setting, and emphasis on process of communication."

Case histories and process research. Case histories have been a respected method of reporting clinical research since the inception of psychoanalysis. Freud published dozens of summaries and a number of lengthy case reports. Among the longer case histories were the cases of Frau Emmy von N., Miss Lucy R., Katharina, and Fraulein Elisabeth von R. in Studien uber hysterie (1895), the case of Dora in Fragment of an analysis of a case of hysteria (1905), the case of "Little Hans" in Analysis of a phobia in a five-yearold boy (1909 and 1922), the case of the "Rat Man" in Notes upon a case of obsessional neurosis (1909 and 1955), and the case of the "Wolf Man" in From the history of an infantile neurosis (1918) (Strachey, 1974).

With the advent of client-centered therapy and Rogers' penchant for studying raw data, there emerged the phenomena of verbatim transcripts in case reports. Rogers' insistance on the audio/visual recording of therapy sessions as a teaching instrument led to the ultimate refinements which made it 
possible to assess the process of therapeutic change (Meador and Rogers, 1973). The application of these refinements generated the publication of entire treatment processes by Rogers and his followers. The classic Casebook of nondirective counseling (Snyder, 1947) contains verbatim transcripts of five separate cases handled by five different therapists and includes a practice exercise for aspiring clinicians. The client and therapist statements are numbered for easy reference and the statements are interspersed with explanations of the client-centered technique by the attending therapist. No attempt to measure outcome was made.

By 1958 the Conference on Research in Psychotherapy reported that the "major emphasis of many of those present had shifted from concern with outcome to concern with process." This was interpreted as a natural advance from research concerned with before-and-after attributes of therapy to studies of the events which constitute psychotherapy "in an endeavor to identify and define the phenomenon of change itself" (Rogers, 1959, pg. 96-107).

Gottschalk and Auerbach (1966) describe three general categories in the field of psychotherapeutic research. Research on the effects or outcomes of personality change through therapy, and research to test or amend theories of personality by data collected in a therapeutic interview, are two of these categories. The third category involves 
research in the process of psychotherapy. This research

concerns itself principally with the course of psychotherapy and not with the ultimate changes in patients consequent to psychotherapy. Process research ranges from the analysis of moment by moment interchange between patient and therapist in one session to summarizing generalizations about long segments of psychotherapy. Process research may also involve studies of the behavior of the therapist to determine what aspects have 'therapeutic effects.' (pg. 5-6). Process defined. Rogers (1967, pg. 14) operationally defined process in terms of "discriminable characteristic sequences...indicative of different degrees of ongoing changing." According to Rogers,

the individual may become more expressive of selfrelated feelings now that he was a month ago, or communicate less of non-self material, and more of self-description. Though such indicators of process are related to outcome, they come from a different order of discourse, representing points in a sequential flow of process events, rather than end points such as cure, recovery, or social adjustment which are terms relating to outcome.

Rogers postulated seven strands or aspects of process. Four of these strands related to the therapy setting: Communication of Self, Personal Construct, Relationship to Problems, and Manner of Relating. The fifth strand is the dimension of Incongruence. The remaining two strands pertain to the quality of awareness and acceptance of feelings L Relationship to Feelings and Personal Meanings 7 and the extent to which this information is used as a referent for thought and action /Manner of Experiencing (Rogers and Rablen, 1958).

Meador and Rogers (1973) also outlined seven stages of process. In the first stage, "communication is about 
externals. There is an unwillingness to communicate self." Feelings are neither recognized nor owned. Next, feelings are sometimes described but as unowned past objects external to self." The person is remote from subjective experiencing. Third, there is much "description of feelings.../ that are 7 not now present." "Distant feelings are often pictured as unacceptable or bad." Expression flows freer about the self as object. Next, "feelings and personal meanings are freely described as present objects owned by the self." Intense feelings are still not now present but there is a "fearful recognition that one is experiencing things." Fifth, "many feelings are freely expressed in the moment." Feelings are owned or accepted and there is a recognition of feelings as a referent and guide. In the sixth stage, feelings are experienced and accepted. The person "risks being himself," trusts others to "accept him as he is in this flow." Finally, "the individual lives comfortably in the flowing process of his experiencing. New feelings are experienced with richness and immediacy..." (pg. 148).

Bugental (1978, pg. 36) defines these upper levels of process in terms of "presence," the quality of "being there." Presence is formally defined as

the quality of being in a situation in which one intends to be as aware and as participative as one is able to be at that time and in those circumstances. Presence is carried into effect through mobilization of one's inner (toward subjective experiencing) and outer (toward the situation and any other person/s in it) sensitivities. 
Presence is being there in every way, in body, emotions, relating, and thoughts. According to Bugental, one of the therapist's basic functions is to get the client present, centered, and life-aware. The client speaks "from a sense of concern rather than about a concern" (pg. 58). "Life is awareness" is a basic tenet of Bugental's existential-humanistic approach to the fundamental nature of being human.

Other case histories. In Search for existential identity, Bugental (1976) offers six dialogues or case reports, along with an introductory chapter and an epilogue. The individual cases are presented in chronological order and are interspersed with behavioral and anecdotal information as well as a first-person report of the therapist's participation in the process. This method of research represents the ultimate in subjective reporting. For Bugental, to report objectively one must make of oneself an object, while a goal of the humanistic approach is to free oneself of "thingness" thereby realizing the primacy of the subjective and the power of presence as the one element that can be truly trusted.

In summary, the precedent for case histories was established by masters in the field of clinical research such as Freud, Rogers, and Bugental. Their general use has increased in recent years. A 1979 computer search of the literature covered by Psychological abstracts yielded 
hundreds of examples of case studies in the group therapy, learning disabilities, medicine, psychoanalytic, and mental retardation literatures. 
Brief therapy has gained increasing acceptance as the public demand for better community mental health places stringent demands on available services. As early as 1946, Alexander and French stressed the importance of planned treatment while experimenting with flexible used of psychoanalysis. They suggested that, as 1 ife becomes more complex through technological advances, an overwhelming number of persons become emotionally unbalanced and thus the need for viable treatment approaches to meet this demand.

Barten (1971) outlined the historical developments leading to the increasing acceptance of brief therapy as a major treatment modality. Among these developments was a recognition of the need for preventive and emergency therapeutic measures, professional acceptance of limited goals for the client in therapy, the inclusion of professionals in other helping disciplines, a commitment to provide for the needs of lower social-sultural groups, and public demand for economically feasible services.

Brief therapy has been described as the "child of bitter practical necessity...due to social conditions" (Fenichel, 1954, pg. 243) and a "compelling necessity /đue tof a public increasingly aware of the importance of mental health" (Bellak and Small, 1965, pg. 2). In a recent review of the literature on short-term therapy, Straker (1977, pg. 813) attributes the "pressing needs of so many for psychological treatment" to "a more sophisticated public 
and third party payment." "Brief treatment," he states, "is both cost efficient and therapeutically sound."

Cost efficiency becomes increasingly important as fees for individual psychotherapy increase to meet the demands of today's inflated economy. Klopfer (1979) estimates this increase to be about 150 percent over the last 10 years.

Lengthening factors. Short-term therapy has its roots in psychoanalytic theory. Some of Freud's early patients were not extensively treated. His original treatment consisted of hypnotizing patients so that he could direct them to recall painful memories which had been repressed. Once the memories were brought into consciousness and openly discussed, the great emotional discharge brought about the relief of hysterical symptoms. Freud and Breuer labeled this process "cathartic hypnosis" or "catharsis" because it reminded them of the physical treatment of giving an emetic or a cathartic to produce a bodily cure. Among Freud's cases surveyed by Malan (1963) were the treatment of Dora for eleven weeks in 1900 and the case of the "Rat Man" for eleven months in 1907. Malan found case histories of successful short analysis in the early literature but they seemed to disappear later on. He found seven documented histories in the German psychoanalytic journals during the years 1909-1914 but none from 1915 through 1920. He felt that the early analysts found the "secret of brief psychotherapy" and then lost it (pg.9) . 
Freud next experimented with a "waking suggestion" in which he would encourage his patients to remember the trauma simply by means of a strong suggestion while they were in the waking state. The third stage of Freud's evolving therapeutic system involved the method of "free association." The patient was directed to talk about anything that came into mind, under the assumption that past events will be recalled more gradually. He concentrated on dreams, fantasies, thoughts, and feelings.

It was at this point that Freud discovered the phenomenon he called "transference" which led to the development of his theory of transference neurosis. The early analyses of relatively short duration were eventually extended into a technique of emotional reeducation requiring a few years of psychoanalysis. The shift from hypnosis to suggestion generated the problem of the patient's "resistance" to recovering some memories. Free association led to the importance of a technique for dream analysis. Methods were developed to interpret transference feelings and dependency. Reeducation for the permanent relief of symptoms created the necessity for a "working through" of feelings (Alexander and French, 1946; Masserman, 1965).

Thus, as the evolution of psychoanalysis unfolded, each new discovery brought a tendency to increase the length of therapy. While the original technique required an authoritative operator, the changes led to the therapist's becoming increasingly passive (Aguilera and Messick, 1974; Alexander 
and French, 1946; Barten, 1971; Malan, 1963). Treatment was allowed to take its own course and the same procedure was followed every time (Alexander, 1946).

Franz Alexander pioneered the research into brief therapy by leading the Brief Psychotherapy Council which met at the Chicago Institute for Psychoanalysis in 1942, 1944 and 1946 (Barten, 1971). Alexander (1946) stated that the traditional technique was neither the most economical, penetrating, nor effective. He suggested the method of designing an individual treatment plan for each patient and recommended "conscious use of various techniques in a flexible manner" to fit the needs of the individual patient. The trend toward flexible treatment plans, then, required a more active role on the part of the therapist and the therapy itself became focused on specific and current problems of the individual patients (pg. 5).

Definition. In formulating a definition of brief therapy, Barten commented on traditional therapy by stating that it "tends to be more passive, reflective, open-ended, and patient-steered...oriented toward feelings, self-

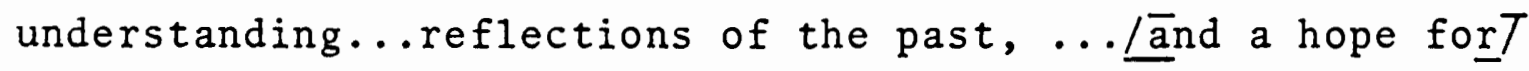
enduring behavioral modifications... as a result of the prolonged exploratory collaboration of patient and therapist." Brief therapy, he stated in contrast, "is characteristically a technique which is active, focused, goal-oriented, circumscribed, warmly supportive, action-oriented, and concerned with present adaptation" (pg. 9). 
Bellak and Small (1965) agree that the therapist is very much involved and active in the process and go on to say that brief psychotherapy is not "easy therapy." "The therapist must be acutely alert to every meaningful communication, while rapidly formulating the common denominators, filling in omitted parts, ... I and 7 simultaneously deciding upon the most fruitful intervention..." They add, "the therapist must foster insight...stimulate working-through. And where these basic aspects of the therapeutic process are not forthcoming, he must invent alternatives" (pg. 6).

Aguilera and Messick (1974) see the therapist (in brief therapy) assuming "a more active role than in traditional methods. He avoids picking up trends not directly related to the presenting problem. The positive is accentuated, and the therapist presents himself as an interested, helpful person ...to help the patient evaluate the reality of his situation in an attempt to modify and change it. Productive behavior is encouraged" (pg. 15).

Time factors. How brief is brief therapy? The number of sessions recommended for successful brief therapy runs the gamut from the specific to the vague and, in terms of numbers, from a single session (Barten, 1971) to nearly a year and a half (Alexander, 1946).

Bellak et al suggest one to six therapeutic sessions of 45-50 minutes duration "or any reasonably limited number... usually under twenty" (pg. 10). Aguilera qualifies this distinction further by separating the one to 20 session 
methodology into the brief category and reserving the one to six session chunk of time for crisis intervention. She outlines the major differences between psychoanalysis, brief psychotherapy and crisis intervention in terms of the goals of therapy, the focus of treatment, the usual activity of the therapist, the indications for choice of treatment, and the average length of treatment. Essentially, she views the goal of psychoanalysis as a restructuring of personality requiring an indefinite period of time. Psychoanalysis is indicated for those individuals with neurotic personality patterns. The goal of brief therapy is the removal of specific symptoms and the prevention of deeper symptoms. The average length of treatment is from one to twenty sessions. Indications for brief therapy are acutely disruptive emotional pain or circumstances where the problems do not require lengthy psychoanalysis. The goal of crisis intervention is limited to the resolution of an immediate crisis indicated by an individual's "sudden loss of ability to cope with a life situation" (pgs. 21-22). Treatment averages one to six sessions.

Selection criteria. According to Bellak, psychoanalysis is indicated "in the presence of good ego strength, the absence of immediately pressing issues, and the presence of chronic widespread and deep-rooted disturbances" (pgs. 1112). He describes brief therapy as a shortened form of traditional psychoanalysis necessitated by the life situation 
of the patient or by the setting in which help is offered. Emergency psychotherapy, according to his description, is brief therapy in situations where a crisis exists. The crisis may take the form of "acutely disruptive emotional pain, severely destructive circumstances, and in situations actively endangering the life of the patient or others." Brief therapy, he believes, is indicated "for individuals who have problems which do not require or are not amenable to psychoanalysis. Brief therapy is also indicated when it is all that is needed or it is all that can be offered in terms of time, money and available personnel. In selecting the appropriate treatment, Bellak considers the acuteness of the presenting situation or its relative mildness, the real-1ife circumstances of the patient and the nature of the situation in which psychotherapy is made available as well as the therapist's ability to clearly conceptualize the nature and dynamics of the patient's disturbance and its responsiveness to treatment. He states that brief therapy has some usefulness in nearly every kind of emotional disorder and is contraindicated only where it was tried and did not suffice, with character disorders, and in all conditions where extensive restructuring of character is desirable.

The criteria for selecting patients suitable for brief therapy and the interest in flexibility of treatment generated a need for guidelines to determine the treatment of choice in these cases. The quest for a choice of approach 
in brief therapy led Alexander to distinguish two general types of psychotherapy -. supportive and insightful. "Supportive therapy is used primarily for the purpose of giving support to the patient's ego with no attempt to effect permanent ego changes; uncovering or insight therapy is used primarily for the purpose of achieving a permanent change in the ego by developing the patient's insight into his/her difficulties and increasing the ability of the ego to deal with them..." Supportive therapy is indicated for persons who are acutely disturbed because of an unusually difficult external circumstance where no permanent change is needed because the person was previously well adjusted and functioning is only temporarily impaired. It is also indicated where there is little hope of permanent change in persons who suffer from severe chronic conditions. In these cases inferiority feelings are combatted with reassurance, guilt feelings with permissive attitudes, and anxiety through the therapist's protective role.

The more recent discussions of brief psychotherapy also draw a distinction between two types of intervention: anxiety-provoking (dynamic) therapy and anxiety-suppressive (supportive) therapy. According to Sifneos (1971), both kinds of therapy can be either long- or short-term. He further subdivides the anxiety-provoking type into (a) shortterm, which emphasizes problem solving and limited dynamic change and (b) crisis intervention, which helps to overcome 
an emotional crisis quickly. He subdivides the anxietysuppressive type into the categories of (a) brief and

(b) crisis supportive, depending on its length of time. It aims to "decrease or eliminate anxiety by use of supportive techniques such as reassurance or environmental manipulation, with or without drugs" (pgs. 82-89).

Sifneos (1972) reviewed records and interviewed patients and therapists at Boston Beth Israel Hospital to develop guidelines for the evaluation and selection of patients. His criteria for selecting patients for shortterm anxiety-provoking therapy require that the patient must be of above-average intelligence as evidenced by exceptional work performance or superior academic achievement. The patient must have had at least one meaningful relationship with another person during his/her lifetime. A "meaningful" relationship was defined as one which included shared intimacy, emotional involvement, trust, and an ability to give and take. Further, the patient must be able to interact with the evaluating psychiatrist by appropriately expressing some emotion during the interview, by showing some degree of flexibility in affect, and he/she must be able to voice a specific chief complaint. Finally, the patient must be motivated for change and willing to work hard during treatment.

In addition, Sifneos developed criteria for evaluating patients' motivation for anxiety-provoking therapy. For an 
individual patient these included the recognition that his/ her symptoms are psychological was deemed crucial. Furthermore, the patient must be capable of introspection, and an honest account of emotional difficulties, an active participation in the treatment, a curiosity about oneself, the willingness to explore and experiment, an expectation of results and the ability to make reasonable sacrifices.

Anxiety-suppressive intervention is offered to severely disturbed patients and aims to decrease anxiety by use of supportive techniques. According to Sifneos, this type of therapy is indicated for patients with a history of recent and rapid decompensation from a precarious level of emotional functioning, lifelong psychological difficulties and poor interpersonal relations. Sifneos required, however, that the patient must have the ability to maintain a job, send out a strong appeal for help, recognize that his/her symptoms are psychological and be willing to cooperate in the therapy. Anxiety-suppressive (supportive) brief therapy includes support, reassurance, encouragement and persuasion, summing up and clarification, counseling and environmental manipulation. According to Straker (1977, pg. 814) the goal is to "achieve anxiety suppression and a reparative restoration to the pre-illness state. If the crisis resolves, the symptoms abate, but little else is changed." In his discussion of short-term treatment, Straker suggests that it is especially applicable for consultation work, for those presently under- 
served or neglected, and for the treatment of patients who present circumscribed problems but who otherwise have a relatively healthy personality. His review of the literature includes studies showing it to be effective as a preventive technique for high risk groups, to reduce the need for rehospitalization and in situations of crisis and acute stress.

Techniques. Since brief therapy has its roots in psychoanalytic theory it follows that the techniques of short-term therapy are adapted from psychoanalysis. The analysis of transference and resistance, interpretation, and free association are used in a modified manner in brief therapy. Other basic procedures include increasing client self-esteem, catharsis, drive repression and restraint, reality testing, intellectualization, reassurance and support, and counseling and guidance (Aguilera).

According to Bellak, positive transference should be encouraged and elicited in brief therapy. It is not just permitted to develop but is sought at the outset and maintained until the end. Negative transference is avoided whenever possible but it is referred to whenever it can be helpful or stands in the way of the progress of therapy. Transference, as he uses the term, refers to the "totality of the patient's relationship to the therapist." It includes "all the non-rational sentiments of the patient toward the therapist including hopes, fears, likes and 
dislikes" while remembering that many of these sentiments may be quite reasonable. In formulating this definition he would hope that the patient at least considers the therapist as a likeable, reliable person who is understanding and accepting. At least, he states, the patient ought to expect that the therapist can help (pg. 40).

Klopfer (1979) explains to graduate students in clinical psychology that the therapist may remind the patient of someone else. He sees transference as the perception of the therapist as endowed with characteristics of another person from the patient's past. He recommends that the therapist search his/her own self to see if he/she is giving off clues to the patient. Patients may also stereotype the therapist by gender, age, clothing, and appearance so that the therapist needs to consider both the reality and the transference with the patient in therapy.

Klopfer describes resistance as an unconscious desire to not fully reveal everything to the therapist while consciously wanting to, of wanting to be not totally understood. It is not the same as caution, which is conscious; resistance occurs later in the therapy. Klopfer suggests that the therapist check out the possibility that he/she could be wrong in analyzing resistance since patient-therapist disagreement is not always due to resistance.

"Direct resistances are those in which the patient refuses to abide by simple requests" of the therapist, i.e. 
not showing up for the appointment or refusing to talk. Indirect resistances include "transference excesses, somatization, acting out, excessive regression, excessive emotionality, and absence of feeling" (Fine, 1973, pg. 20). 
Many types of psychotherapy have been examined in research with retardates. Among these are play therapy, artistic expression such as finger painting or dancing, behavior modification, psychotropic drugs, individual therapy, and group therapy with retarded clients or with the families of retarded persons. This review is limited to the research concerning individual psychotherapy with retarded children and adults.

Definition. Mental retardation has been difficult to define because of the long controversy over theories of intelligence (Robinson and Robinson, 1976). Early attempts to define the concept were made by Tredgold (1937, 1942), Dol1 (1941), Heber $(1959,1961)$, and Sarason (1965). These historical definitions included one or more of three major criteria: (a) mental retardation originates during the developmental period, the upper limit of which is set at 18 years, (b) it involves the concept of mental subnormality, usually determined by an intelligence quotient, and (c) mentally retarded individuals are socially inadequate. While general agreement seems to exist about the first criterion, the concepts of IQ and social inadequacy have been subject to criticism (Prehm, 1974).

Contemporary definitions of mental retardation are discussed by Robinson and Robinson (1976). In the second edition of The mentally retarded child they review Mercer's 
(1973) classification of previous definitions as falling into either the pathological category following the medical model, or the statistical category following the intelligence testing model. Mercer proposes a third alternative, the social system perspective, under which a person is deemed retarded only because of a label given by some social system such as the schools. Mental retardation, according to this point of view, becomes a role or status rather than a personal characteristic. Robinson also discusses the operant conditioning perspective developed by Bijou (1966) which defines mental retardation as "impaired development due to failure of coordination of stimulus-response functions which make up behavior repertoires" (pgs. 24-33).

A widely accepted definition appears in the American Association of Mental Deficiency (AAMD) revised manual on terminology (Grossman, 1973, pg. 30). It defines mental retardation as follows: "Mental retardation refers to significantly subaverage general intellectual functioning existing concurrently with deficits in adaptive behavior, and manifested during the developmental period." As part of the definition "mental retardation" describes current behavior. "Intellectual functioning" is usually measured by one of the standardized tests such as the Wechsler or the Stanford-Binet. A "significantly subaverage" performance on one of these tests would be indicated by a score which is more than two standard deviations below the mean or average. 
This represents a score of 69 on the Wechsler and 67 on the Stanford-Binet. "Adaptive behavior" refers to individual levels of personal independence and social responsibility compared with peer group and cultural norms, and "developmental period" reaches the upper limit at age 18 (Robinson, pg. 30) •

Classification. Retarded people were once classified as morons, imbeciles and idiots depending on their level of disability. In 1954 the World Health Organization recommended use of the words mild, moderate, and severe subnormality in an attempt to dilute the infamy of the previous terminology (Robinson).

In America, the public school system has adopted a legal-administrative method of classification. Children who are identified as "educable" and "trainable" are offered special classes in general education and work experience. These boys and girls are usually mildly and moderately retarded. The severely and profoundly retarded are classified as "custodial." Some of these youngsters are permanently institutionalized while others are offered opportunities to participate in activity and training centers (Prehm, 1974, pg. 14; Edwards, 1978).

The current AAMD system of classification by severity of symptoms is the most widely used today (Robinson, pg. 33). This system describes the retarded person in terms of intelligence, adaptive behavior, and etiology. 
Intelligence is measured by standardized tests. Classification is based on standard deviation units rather than on IQ scores. Levels of retardation show up as follows:

-2.01 to -3.00 standard deviations, mildly retarded

-3.01 to -4.00 standard deviations, moderately retarded

-4.01 to -5.00 standard deviations, severely retarded

Below -5.00 standard deviations, profoundly retarded Adaptive behavior can also be measured by standardized scales but because the instruments are less precise than most intelligence tests, the AAMD recommends that clinical judgment be used to compare the client's behavior with the general descriptions in the manual.

Retarded persons can also be classified by etiology. Most of these etiologies are described as clinical types such as chromosomal abnormalities and gross brain disease, but environmental influences and other conditions are included (Prehm, 1974). Robinson and Robinson (1976) devote several chapters to discussions of etiology and special education. History. For the most part, mentally handicapped people have been either ignored or maligned. According to Wall (1978), they were considered as objects of "scorn and persecution" (pg. 3) by the ancient Greeks and Romans. They served as "fools and jesters" (pg. 3) during the medieval period. Martin Luther called them soul-less, the Eugenic movement labeled them "tainted" (pg. 3), and the Nazis 
selectively killed them. Until very recently only a few enlightened individuals attempted to care for and educate them. Among these were Jean Itard in 1800, Johann Guggenbuhl and Edouard Seguin in the middle of the nineteenth century, and Maria Montessori in the early 1900s (Robinson; Wa11) .

In the United States from the mid $1800 \mathrm{~s}$ the trend has been toward institutionalization. The first institutions were built as schools for the purpose of teaching the mentally retarded at least minimal skills so they could function in society. Because the expectation was of complete and rapid cures, many people were disappointed and ideologies soon changed. By 1880 the term "school" was replaced by "asylum" and the institution was redesigned to shelter rather than educate the mentally deficient (Wolfensberger, 1975, pg. 28) .

Intelligence testing on a large scale generated spurts of interest in mental retardation during both-world wars but it was not until the middle of this century that serious attention was turned to the problem. In 1950 parents formed groups which eventually became known as the National Association for Retarded Citizens (NARC). This group started the special classes for trainable retarded children which were eventually administered by the public schools. The 1954 Supreme Court decision against school segregation added impetus to the movement by declaring that education was a 
right, not a privilege. In 1972 the courts finally wrote a decision specifically for retarded children. The case of the Pennsylvania Association for Retarded Children et al $v$. Commonwealth of Pennsylvania et al forced the commonwealth to seek out and provide special education to all children who needed these services (Robinson).

Mental retardation became more "respectable" in the 1960s when the nation learned that President Kennedy and Vice President Humphrey each had retarded members in their families. President Kennedy then ordered the President's Panel on Mental Retardation (1962) to explore the possibilities of preventing and curing mental retardation, and to appraise the existing programs in the country. Their report recommended

action in research, preventive mental health measures, strengthened educational programs, more comprehensive and improved clinical and social services, improved methods and facilities for care, new legal and social concepts of the retarded, help to overcome manpower problems in professions concerned with retardation, and programs of education and information to increase public awareness (Robinson, pg. 46).

The International League of Societies for the Mentally Handicapped met in 1968 and wrote a declaration proclaiming that all mentally retarded persons have "the same basic rights as other citizens of the same country and the same age" (Leland and Smith, 1974, pg. 150). The league formulated this declaration in accordance with a philosophy called "normalization." This principle holds that all individuals have the right to be treated as normally as 
possible. Guided by this principle, many mildly retarded children are spending a large part of their day in regular classes instead of special education facilities. Retarded individuals who were institutionalized are being returned to their families or placed in foster homes or group homes. They attend activity centers or sheltered workshops during the day.

Research. The change in attitudes toward the mentally retarded during the last three decades was accompanied by an increasing interest in the efficacy of psychotherapy with clients of below-normal intelligence. Therapists had been influenced by the opinions of popular leaders who argued against the feasibility of psychotherapy with the mentally deficient (Robinson). In 1925, Morgan wrote that persons with low intelligence were less likely to have mental conflicts than brighter persons (Neham, 1951). Yet a few early researchers claimed success using both the classical (Gunzberg, 1975) and client-centered approaches to therapy (Thorne, 1948). Contemporary reviewers are of the opinion that retarded clients have the same emotional problems as the normally intelligent (Selwa, 1971). Indeed, they may need even more services because they encounter more crises while growing up (Halpern, 1974).

A number of early researchers discussed techniques which might be appropriate with mentally retarded individuals. Thorne (1948) reported using non-directive methods success- 
fully on children with disciplinary problems at a state school. He found the methods developed by Rogers very effective in assisting the children to express and clarify their feelings and emotions.

Neham (195I) reviewed studies with mentally deficient soldiers, the use of projective techniques to determine personality disorders in the mentally deficient, and experiments in environmental, occupational and relationship therapy. She concluded that the mentally retarded experience "personal anxieties, frustrations, fears and mental suffering" (pg. 567) and that various techniques including psychoanalysis and non-directive therapy, as well as more directive and supportive approaches, showed favorable results.

Burton (1954, pg. 488) labeled psychotherapy with the mentally retarded "an unchartered field." In his review of historical conceptions he complained that insight had been oversold as a criterion for improvement since it exaggerated verbal, intellectual and conceptual qualities at the expense of feeling and emotion. He believed that psychotherapy could help retarded individuals face their shortcomings by freeing them from conflictual and anxious immobility. Conventional techniques would have to be re-adapted and goals would have to be reduced for this special population.

Weist also reviewed the literature in 1955 and reached the conclusion that retarded clients could reach a certain 
stability within their own limits by experiencing feelings of acceotance and belongingness. Reality could be made more appealing by the use of psychotherapy.

Sternlicht (1966) extensively reviewed the research studies from 1955 to 1966. He suggested that the available procedures offered a choice of tools to the analyst. Among them were non-verbal techniques, discussion therapy, "very brief therapy...in simple language" (pg. 289), directive and non-directive types, projective techniques, fine arts, performing arts, psychodrama, relationship theory, egosupportive therapy, educational therapy, conditioning therapy, and play therapy. He noticed one common factor in all these techniques: effective communication. His review alsc explored some novel approaches such as hypnosis, shadow therapy, and fighting methods used with acting-out adolescents.

In a survey of professional psychologists, woody and Billy (1966) found acceptance of a variety of techniques with an eclectic approach ranked first, and client-centered therapy second. Their respondents found that therapy could benefit the retarded in the areas of

institutional adaptation, motivation for learning, peer group associations, familial relationships, control of unacceptable behavior, resolution of conflicts with authority figures, return to the home, personality modification, return to the community, and improving employability (pg. 23).

Szurek and Philips (1966) attempted to debunk the myth that psychotherapy is ineffective with people of below-average 
intelligence. They presented case studies of their therapy with retarded clients and cautioned clinicians to be aware of their own prejudices in perceiving the retarded as untreatable. They found that the mentally retarded can befefit from therapy to alleviate emotional disorders which "inhibit learning, distory development, and impair social adaptation," that the same techniques and methods can be used as with normally intelligent people, and that the attitudes of therapists who see retardation as a hopeless condition "detract from the success" of their work (pgs. 243-244).

Bialer (1967) discussed the difference between outcome studies and process studies. He stated that the bulk of research had been concerned with outcome studies which attempt to answer the question: "Is therapy effective with the mentally retarded?" This question is no longer pertinent, according to Bialer, since numerous investigations have indicated that benefits accrue. Process research, on the other hand, investigates the active elements involved in treatment and seeks an answer to the question: "What methods and procedures work best with which populations and what is the nature of the experience?" Bialer stated a belief that research must turn to the nature of the process, but reported that the literature on process with the mentally retarded was nonexistent.

Gardner (1967) denied the feasibility of traditional psychotherapy with the mentally retarded. He felt that psychologists should act only as a consultant to others, as a 
manipulator of the retardate's environment, or occasionally as a behavior therapist. Halpern (1968) took issue with Gardner's sweeping stance by calling for further exploration to find which techniques work best, under what circumstances, and with whom.

Lott (1970) quoted many references in his review of the literature on psychotherapy with the mentally retarded in order to counteract the usual impression that mentally retarded persons cannot be responsive to talking or relationship therapy. According to Lott, the literature reflected a minimal but increasing interest in mental retardation.

Selwa (1971) investigated the special needs and characteristics of retarded children while attempting to establish a program for provision of psychotherapy by school psychologists. She noticed that mentally retarded children have the "same emotional and social problems as other children, such as sibling rivalry, puberty onset, parental pressures, etc." (pg. 12) but that they had less intelligence to cope with these difficulties. The intellectually handicapped child also has feelings and attitudes about these limitations which have an effect on both the retardate and the family. Because of these special problems language and interaction should proceed within the comprehension and range of the client. Selwa suggested that therapist attitude is critical in this situation. In order to be effective the therapist "must believe that retardate therapy is a promising endeavor" (pg. 14). 
Gunzberg (1974) reviewed the early studies through the 1960 s and observed that most were done in institutions and with groups. He severely criticized the methodology which had been used and stated that the work reported appeared to have been carried out by complete novices.

Halpern (1974) wrote that the curricula for retardates in the schools includes vocational training as well as general education. Adult retardates fail at vocational adjustment, he believes, because of personal and social deficiencies rather than job-skill lack. They have problems in making decisions, they cannot tolerate long periods of non-reinforcement, they lack appropriate training, fail to observe safety rules, will not risk failure, lack initiative, cooperation and cheerfulness, and their social behavior is inappropriate. Halpern suggested that a counselor with a retarded population would face some problems more frequently than with the normally intelligent, but that uniquely applicable techniques were not needed. Halpern cautioned counselors and therapists against the assumption that insight is necessary for change. He posited some explanations as to why verbal counseling might work with retarded clients.

One possible explanation is that aspects of the relationship other than introspection were the primary agents of client change. Possible sources of gain might include the learning of new and relevant information via simplfied instruction or the opportunity to model one's behavior after an admired and well functioning adult (pg. 273). 
The attitudes of therapists towards psychotherapy with retardates were also discussed by Robinson and Robinson (1976). They suggested that therapists may see the handicapped as "uninteresting, unattractive, and perhaps even somewhat repulsive" (pg. 393). As the clinician gains experience with the retarded and their families, however, their attitudes tend toward sympathy, respect for their needs and goals, and appreciation of their individuality.

In summary, research in the field of psychotherapy with retardates has found that both directive and non-directive techniques are effective with this population (Thorne, 1948; Neham, 1951; Burton, 1954: Sternlicht, 1966; Woody and Billy, 1966; Szurek and Philips, 1966). This literature further suggests that the therapist's attitude toward working with retardates plays a large role in determining success (Selwa, 1977, Robinson and Robinson, 1976). The case studies that follow illustrate a number of the techniques described in this and the previous chapter. The clients who participated in the study were all of below-normal intelligence and the attitudes of the therapist, supervisor, counselors and staff the the Portland Habilitation Center were all positive in relation to the efficacy of psychotherapy with retarded adults. 


\section{Case Studies}

The following case studies were conducted with clients at the Portland Habilitation Center. The presenting problems of these individuals included (1) a transition to independent living following the recent death of a parent; (2) overcoming slowness and adjustment to new intellectual potential;

(3) adjustment to sterilization and overcoming acting out; and (4) awareness of bodily self and others.

Three of the clients were of below-normal intelligence as measured by the Wechsler Adult Intelligence Scals (WAIS). in the range from 50 (moderately retarded) to 55 (mildly retarded). The fourth client had an I.Q. of 79 (borderline retarded). Two of the clients were male, two female. Their ages ranged from 21 to 39 years. Two clients lived in group homes, one shared an apartment, and one lived with parents. Two of the clients were naive to therapy while the other two had had previous counseling. 
Marian was referred to therapy to aid her in making a transition to independent living. For most of her life she had been sheltered at the home of her parents. At 39 her surviving parent died, and at the time therapy was initiated she was in the process of moving to an apartment which she would share with another woman. Her therapy was designed to help her deal with the loss of her parents and to assist her in adapting to her new living situation.

Prior to therapy, Marian had been advised by family members to not dwell on the subject of her parent's death. The the: apist assisted her in dealing with her loss by granting permission to express her grief during the sessions.

Marian was a well-groomed woman with good social skills but with a sub-assertive personality. As soon as she moved into the new apartment she was required to use her skills in developing interpersonal relationships, specifically with her new roommate and with a neighbor who was also a client at the Portland Habilitation Center. The therapist assisted her in that development by providing opportunities to discuss relationship issues as they occurred and by teaching assertiveness skills through guided fantasy, modeling and role playing, "I" statements, and discussions about fersonal rights.

Early in therapy, Marian frequently made tangential statements in response to the therapist's comments. The therapist suspected this might be due to a resistance on the client's part to revealing information about her feelings. 
Marian's "feelings" at that point appeared to be simple repitions of the therapist's statements. Further probing revealed that Marian might have been "transfering" to the therapist feelings that originated with an older sister. Since transference, in the broad sense, was being actively sought and encouraged, the therapist deliverately attempted to separate those associations by interjecting statements that would be contrary to a sisterly edict. This encouragement led to the development of the trust relationship necessary for therapeutic work as Marian learned to relate to the therapist as a resource person and confidante.

During the course of therapy Marian learned to assert herself in some instances and to experience and share real feelings. The therapist recommended that Marian receive continued support and reassurance that her feelings were valid and could be trusted. 
Name :

Age :

Date of birth:

Living arrangement:

Parents:

Siblings :

IQ, Full scale:

Verbal :

Performance:

Classification:

Medical diagnosis:

Medications :

Other tests:

Total jessions:

Duration:
Marian

39

March 18, 1938

Shares an apartment

Deceased

Sister, Darlene, 50, local adaress

Brother, 49, Iives out of state

Moderate retardation

None

None

None

16

Twice a week for 6 weeks with one absence, then once a week for 5 weeks 12 to 38 minutes

History. This 39 year old woman had attended the portland Habilitation Center for nine months. She had spent most of her life in a sheltered existance at her parent's home and had never held a job. Her father died four years earlier and her mother passed away two months ago. At the time therapy was initiated, she was Iiving with her 50 year old married sister.

Marian was described as quiet and shy, but with good social skills. She was a prime candidate for an independent 
living program that had just been instituted, and was scheduled to move into an apartment which she would share with another retarded woman. A number of her neighbors would also be clients from the center.

Initial interview. The therapist explained the thesis project and requested Marian's participation. The informed consent form was read aloud and Marian signed it.

Rapport was established through a discussion of Marian's present living situation. She talked about her sister's house and of a recent plane trip she took to attend a wedding is wisconsin. She also mentioned her mother's recent death.

Marian was extremely friendly throughout the session. She seemed to adopt the attitude that she was visiting with a friend. Her grooming was immaculate, reflecting great care in her appearance.

Marian's affect seemed appropriate. She showed pride in her ability to travel alone, she wept as she told of the loss of her mother, and laughed pleasantly as she anticipated moving into the new apartment.

First session. The therapist's agenda for this session called for a probe into Marian's feelings about moving into the apartment. She had a mental list of things she must do and of things that were already done. Her sister was apparently assisting her in organizing the move and had made her a gift of a cookie jar for her new home.

Marian spoke animatedly and appeared pleased about the impending change in her living arrangement but several times 
during the meeting she made tangential statements to change the subject.

$\mathrm{T}$ : What day are you moving?

C: Last day on a Wednesday.

$T$ : So Thursday night you'll be in your own apartment?

C: I haven't seen anybody down the hall.

These tangential statements could have been due to resistance on the part of the client to discuss the apartment with the therapist. However, as will be seen by session three, heavy transference was occurring and Marian might have been projecting attitudes towards her sister to the therapist. In answer to questions about some phase of housekeeping, for example, Marian would carefully recite the procedure as though repeating a set of memorized instructions, probably generated originally by the sister.

C: I burned the meat but I didn't mean to burn it. I have to turn it over. I have to turn it real low. And then you have to fix the gravy and stir it all up.

Marian had a wide range of facial expressions which seemed appropriate to the discussion. Her associations to most prompts, however, were concrete.

$\mathrm{T}$ : What kinds of things do you have planned for yourself?

C: Oh like playing cards and I have a typewriter.

T: What do you do with your typewriter? 
C: Put my hands on the typewriter. Learn to practice on the typewriter.

The session lasted 15 minutes.

Second session. The therapist continued to lead a discussion about the move to the apartment which generally involved concrete statements about people, places or things. The therapist was not able to get Marian to convey any information about how she felt about the move. When she used words that might express emotion they were simply repetitions of the therapist's query.

$\mathrm{T}:$ Are you excited?

C: I am excited.

The session lasted 15 minutes.

Third session. The discussion was less directed than usilal as the therapist continued to urge Marian to divulge more of what was important to her. The technique used was a guided fantasy during which Marian was coached to imagine herself in the new place and was asked to talk about how it felt to arrange things and put them away. Through this exercise, Marian was able to select the room she wanted for her own bedroom and to later assert her preference for that room, but the words she used to express that imagery were limited to a physical description of the size of the room, the location of the windows, etc.

Later in the session Marian said she was glad to be going to the apartment because her family would be more on 
their own and would not have to concern themselves with taking her along when they wanted to go somewhere.

As Marian spoke, the therapist began to suspect that much of what Marian was saying was repetitious of what she had heard her sister say and what she surmised her sister would expect to hear from her. In addition, it was also suspected that the observable appropriateness of her affect may have been simple mimicry of facial expressions rather than genuine affect. The therapist's agenda for the next session involved an exploration into how much of her expression was genuine.

The session lasted 15 minutes.

Fourth session. Marian moved her belongings into the apartment the evening before the session and was planning to go there after work to spend the night. The therapist led a discussion about the apartment once again and asked Marian to phrase her comments in the first person by means of "I" statements. This assertive training technique forces the speaker to participate in the action by focusing on herself as the teller. The therapist modeled the technique and Marian learned quickly. The therapist let Marian know that she seemed more real to her when she included herself as part of the story.

Client and therapist also role-played a few situations in which Marian might have to assert herself at home such as how to furnish and decorate her room or how to decide with her housemate on what to cook for supper. 
The session lasted 20 minutes.

Fifth session. The session continued with a discussion about the apartment. The move had been completed and the women were getting settled. Marian talked about the experience mostly in terms of the work that needed to be done. There was evidence that transference was occurring. The therapist again felt that Marian was reporting as if to her older sister and was limiting her remarks to the type of statements her sister would want to hear.

$\mathrm{T}$ : So you are really busy on weekends. You clean house and do your laundry.

C: Clean the tub out and sink. Clean the kitchen out and sink and clean the windows and sweep the floor in the dining room and front room and be sure the doors are locked and the back door. Everything.

$\mathrm{T}$ : Sounds like a lot of work. But you think it's fun too?

C: But then I have to clean my room and straighten things up in my bedroom and she does the same thing with hers.

The therapist then shifted to a line of discussion that would begin to separate Marian's perception of the therapist from her associations with her sister.

$T$ : I haven't heard you say anything about having time to relax. Have you had a chance to yet?

C: No. Busy, busy, busy. 
About 21 minutes into the session the therapist asked Marian to imagine the scene and to describe her bedroom and how it felt to spend her first night in the new bed. Marian was not able to express the fullness of the experience but she was able to describe a certain amount of new-found comfort.

T: Tell me what it felt like when you got into bed with new sheets and new blankets.

C: When I got into bed the first time--sleep better then. I move my legs around. The other bed is so short you know, it cramped in my legs you know. Like I didn't want to sleep in it. I can roll over once in awhile.

The session lasted 26 minutes.

Sixth session. Discussion about the apartment continued with Marian describing the work that needed to be done. During the session Marian made ien references to her sister. She talked about things her sister did for her and things her sister expected of her.

About twelve minutes into the session, the transference shifted from projected feelings towards the sister to a direct question of the therapist herself.

C: She thinks I'm supposed to roll it up every might.

$\mathrm{T}$ : What does she say to you?

C: That I should roll my hair up every night. Do you think it needs all the curlers? 
$T$ : Looks nice the way it is. What would happen if you just washed and blow-dried it?

C: It would come out curly.

T: Why do you need to roll it up?

c: I don't have to roll it up. It just needs--um.

$T$ : Cause your sister says you should.

C: Yeah. My sister says I should. I was too tired last night. That gets tiresome doing it every night.

$T$ : You don't agree with your sister then.

This session marked the beginning of a struggle for Marian between dependence on a sister who was careful to oversee every aspect of her life and a need to make her own decisions about how she wanted to live.

The session lasted 17 minutes.

Seventh session. During this session we played the Ungame. The Ungame is a board game that uses numbers on a pair of dice to advance players around the board. The stopping places suggest other moves or tasks for each player to perform. Cards elicit answers to questions or request action from a player, such as:

What do you like to do when no one can see you?

Were you impatient today?

What is your favorite sport and why? The questions obviously lead to concrete responses but frequently trigger free associations as well. 
Marian associated the word "alone" to her housemate's need for privacy while she was recuperating from surgery. Marian's friend, Nancy, was pressuring her to spend the night at her house while her housemate, Marilyn, wanted her to stay at home but not have any friends in to disturb them. Marian wanted to go with her friend but did not want to hurt her housemate's feelings. Marian had decided to wait at least a month until Marilyn was feeling better before she stayed away overnight. Nancy accused her of "mothering" her roommate. Marian used nine minutes of the session to explore her options and talk it out, and concluded that she could be a helpful friend to Marilyn without "playing mother" since Marilyn had helped her at times.

It appeared that Marian would stand by her decision to postpone her overnight visit until Marilyn was feeling strong enough to say by herself. The therapist praised her for her ability to withstand Nancy's pressure and to defend the decision she felt was right for herself.

Marian made no reference during this session as to what she should or ought to do. It was clear that she was struggling with a decision that would be fair to everyone but it was also clear that the final outcome would be the one with which she felt most comfortable.

The session lasted 24 minutes. The tone of the meeting was similar to that at the end of the previous session. She was still stating a need to make her own decisions about how 
she was going to live. However, Marian was more in charge of herself than she had been at previous sessions. Her attitude toward the therapist, at this time, seemed to shift from one of reporting to an overseer towards one of utilizing a resource person.

Eighth session. Marian talked mostly about plans for Christmas and about a dance she had attended on the weekend. The trend of transference begun in session three was progressing to where the therapist continued to emerge as a being apart from Marian's sister. For example, during a brief discussion about the apartment, Marian questioned the therapist about the size of her own kitchen, her stove, etc. She mentioned her sister only once.

Marian reported that she was definitely postponing her overnight visit because she said it would upset Marilyn. She also expressed concern about being quiet in the mornings and had begun to meet Nancy at her house for their daily walk to the bus stop.

It seemed that Marian was trying to be considerate of her roommate's wishes. The therapist planned to pursue the trend toward accommodation during upcoming sessions in an attempt to determine whether or not Marian's needs were also being me.

The session lasted 12 minutes.

Ninth session. Marian continued to help her roommate but also ventured to invite guests for dinner while Marilyn 
was away. She appeared to be proud of having prepared the entire meal herself.

C: I fixed the spaghetti first and then I used some sauce, mushroom sauce, and then I used the plain sauce, and then I fixed the hamburger. I fixed them into little round balls.

$\mathrm{T}$ : Meat balls.

$C$ : Yeah. I had some meat left so I put it in the freezer. I fixed hot tea. Then I had coffee for myself. Then I had some dessert from last night, a snacking cake.

Discussion of the impending holiday released some of Marian's feelings of resentment at having to spend Christmas at her sister's house when she was just beginning to enjoy her own place. Her sister would not have a Christmas tree because they were still mourning their mother's death. This train of discussion led to the subject of her mother's funeral.

C: I've got to start a whole new life for myself and not cry myself out any more and not talk about it.

$T$ : Was it your cecision to not talk about it?

C: Decided I should talk about it but I don't want to talk about it. Cause my mother is up in heaven, that's what my brother told me. Made me feel bad. The Lord wants her. When it's time to go it's time to go. 
$T$ : You miss her.

C: Yeah. I miss them both.

After a few moments of silence Marian changed the s'dlject to bicycle riding next spring. During the session her affect had ranged appropriately from delight to sadness.

The session lasted 21 minutes. Marian used about five of those minutes to express her grief.

Tenth session. During this session Marian commented on her roommate's physical complaints and lack of cooperation with Marian's plans. Marian still wanted to spend a night at Nancy's or to get away for an evening but Marilyn did not want her to go. Twice during the session, Marian invited the therapist to visit her apartment and meet her housemate.

Marian was still interested in riding her bicycle but said she could not because her sister would not allow it. In exploring Marian's motivation for always being nice, she said she was afraid of being manhandled by strangers. When she was frustrated, angry, or sad, she directed the anger toward herself and hid (on one occasion in her sister's closet) until she had calmed down.

The session lasted 23 minutes.

Eleventh session. The therapist had visited Marian the evening before to meet Marilyn and tour the premises. Marian had requested the meeting so that the therapist could observe the roommates' interaction in their own house and perhaps 
discuss some of Marian's needs with Marilyn. The therapist found Marilyn to be a quiet, well-groomed young woman. Both women appeared to move comfortably about the apartment and to have established a friendly rapport. There was no opportunity for discussion, however, as several other people were also visiting that evening.

Marian was being urged to visit her sister for the holiday weekend by both her sister and her roommate. She asserted herself, however, by declaring that she was home and that she planned to stay home for the holiday. She further stated that she would invite her friend, Nancy, to spend the night with her while Marilyn was away.

Marian reported that she was still concerned about complying with Marilyn's wishes at the expense of her own. The therapist role-played some situations with her so she could learn the language and technique of negotiating with Marilyn for her own rights.

$\mathrm{T}$ : Perhaps when the infection clears up she'll be easier to get along with.

C: When she gets back to normal maybe she and I could go bowling together.

$\mathrm{T}$ : So you'd like to make friends with her, wouldn't you?

C: She's not ready. She doesn't like me to have Nancy over there because Na:?cy makes too much noise.

$\mathrm{T}$ : Ask them both for some cooperation. Do you think you could do that? 
c: Ya. She doesn't want me to go out and she doesn't want to stay by herself.

$\mathrm{T}$ : Let's address the issue right now. I'll be Marilyn. Marian, I don't want you to go out because I feel lonely when you're not here.

C: I would like Nancy to say over here all night with me so we could have some fun together.

$\mathrm{T}$ : When do you want Nancy to come over?

C: Maybe Monday night.

T: I have to get up and go to work on Tuesday. Why don't you have Nancy over Sunday. night when I'm not home?

C: Sunday would be fine.

T: The word for what we are doing is "negotiate.," Talk it over until you are both satisfied. Keep at it until you find something you can agree on.

The session lasted 20 minutes.

Twelfth session. Marian reported spending the holiday at her apartment with her friend. She had been observing Nancy's relationship with her boyfriend and expressed an interest in getting a boyfriend for herself.

Marian also reported reading a letter from her brother in which he stated that it was nonsense to keep writing the same thing over and over about their mother. Marian said she wanted to write to him about the new apartment so she could comply with his request to change the subject of her letters. 
The therapist offered to help her write the letter if she wanted help.

The session continued with a discussion of Marian's relationships, especially with her housemate and her sister. Marian said she understood that her sister was trying to help but said she didn't like having her sister tell her what to do, even over the telephone, since Marian usually felt compelled to follow through and carry out the orders. This was difficult for Marian to accept because she said her mother had never treated her that way. When speaking of her sister, Marian's body became perceptively tense. During the session she became tearful and stated that her feelings were hurt. She said she was afraid to tell her sister how she felt because she might be forbidden to visit with her afterwards. The therapist continued to work with her on improving communications by rehzarsing ways of telling her sister truthful statements about her feelings. Marian practiced expressing her fear and resentment to her sister in ways that would keep their relationship intact. The therapist spent five minutes toward the end of the session summing up and clarifying feelings for Marian.

The session ended with Marian's statement to the therapist regarding how she felt about coming to therapy.

$\mathrm{T}$ : It takes a little practice. You can practice on me. You can even tell me how you feel about me and that would be all right. 
C: I feel I can come in and talk to you and uh it makes me feel happy, feel good and so I don't hurt myself .

Transference was shifting from seeing the therapist as a resource person to using the therapist as a confidante.

The session lasted 38 minutes.

Thirteenth session. During this session Marian said she had been bowling and had stayed overnight at Nancy's during the weekend. In addition, one of the "boys" in a neighboring apartment had been planning a party and had asked Marian to make a potato salad. She offered to bring a dish but asserted herself by saying she preferred to make a gelatin dessert. She also reported asserting herself at the Center by telling one of the clients to stop bothering her. The therapist praised her for her competence in standing up for herself.

The last part of the session was spent in discussing "shoulds" and "oughts" as they relate to feelings. The therapist offered Marian a list of personal freedoms which they read aloud and discussed in some detail. 2 For example, one of these statements was "say what I feel and think instead of what I should feel and think." These statements of affirmation were another technique in assertive training.

2 The list had been compiled by Mary oldford, instructor in Assertiveness Training for Women, as part of a seminar presented at Clackamas Community College in Oregon City, Oregon. 
The session lasted 22 minutes.

Fourteenth session. Less than two minutes into the session Marian reported being so upset during the weekend she had to go for a walk with Marilyn to "cool off."

c: I got a little upset Saturday you know. She's (her sister) been calling all Saturday and all sunday. She thinks I shouldn't be going to the other apartment. Over to the other kid's house. They were having a party you know.

T: I can hear that you're upset. Did she way why?

c: Could get myself in trouble with this boy. She doesn't think I should be around boys.

$T$ : What do you think?

c: It's my decision to do. It's not hers. It's mine. It's my life. Start a new fresh life and think I'm in charge but I'm not. I'm a woman. I'm adult. I just can't, can't be a child the rest of my life. I can't.

$\mathrm{T}$ : You think she's trying to keep you a child.

C: That's probably what she's doing. I'm a grown woman. I can't be childish all the time.

Further discussion uncovered the information that her sister called to warn her that if the directors of the Center found out about her visiting with the "boys" she would be forced to leave the apartment. Actually the opposite was true since it was the Center's apartment program managers who were arranging the parties and encouraging Marian to have fun. 
Marian said she wanted to straighten it out with her sister but was reluctant to confront her because she was an "old hothead." With the therapist's encouragement she started to rehearse a telephone dialogue with her sister but changed her mind and informed the therapist that she and the apartment managers had colluded to keep the parties and men friends a secret from the sister.

Since the therapist was planning to decrease the intensity of the sessions in preparation for termination, the therapist supported Marian's decision and encouraged her to nurture the liaison with her new support system.

Marian spent most of the session expressing feelings about her sister. She used as much as five minutes at a time, three times during the session, in uninterrupted talk and shared some concerns with the therapist about having feelings. At twelve minutes into the session the following exchange took place.

C: She thinks I do everything wrong. I'm adult. I'm a woman.

$T$ : And right now you're angry.

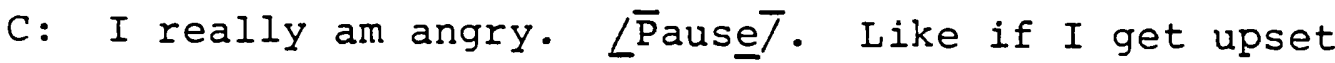
could that be a breakdown or anything?

T: It's perfectly normal because you are a grown woman, an adult, and you want to be treated like one. When someone treats you like a kid you have a right to get angry. 
C: I thought maybe that could be like getting nervous and a breakdown or something. Could that be it?

$\mathrm{T}:$ It's very normal.

During this session Marian also talked about going bowling with this "boy" and of talking with him at her apartment. She said, too, that they were looking for a boyfriend for Marilyn. The therapist learned that Marian had never had sex training. She was not ariare of the fact that men and women sometimes slept together and was surprised that Nancy had not told her. The therapist asked for and received Marian's permission to enroll her in a sex training class at the center.

The session lasted 35 minutes.

Fifteenth session. During this session Marian reported being nervous as she anticipated a visit from her sister. She had become involved with a man and did not want her sister to find out.

This new relationship was also creating friction with her friend, Nancy. Marian said she was made to sleep on Nancy's sofa until three o'clock the previous morning because Nancy was sharing her bed with her own boyfriend. Marian's boyfriend suggested this was not fair to Marian, causing Nancy to be angry with him.

Marian said she intended to go on seeing her male friend while she searched for ways to deal with Nancy and her sister.

Marian looked tired and visibly upset. She kept her eyes down during most of the session. Her head drooped and 
she frequently pulled on hangnails. She wore an almost tearful expression and spoke as though she had a "lump" in her throat. The only time she brightened and smiled was when she said she liked the man and that he liked her.

The session lasted 25 minutes.

Sixteenth session. The termination session was brief. Marian had been forbidden by her sister to discuss her feelings toward her sister or to mention her sister's name in therapy or in the thesis. She was also forbidden by her sister to see her boyfriend except in a group and she had been told that he was not to touch her. Marian was obviously upset and appeared to be afraid of saying anything she had been forbidden to discuss. Many of her statements became, once again, tengential to the subject under discussion.

$\mathrm{T}$ : I thought we were making good progress in looking at those kinds of things.

C: I went to church sunday morning.

Since the session was uncomfortable for the client and since there would be no time in the future to resolve any new business, the therapist spent a few minutes on summarizing Marian's progress of the past weeks and offered recommendations for her future progress.

The session lasted 12 minutes.

Summary. Marian was a 39 year old woman who had led a sheltered life until her only living parent died two months earlier. She was a well-groomed woman with good social skills 
who had been invited to participate in an independent living program by sharing an apartment with another retarded woman. She had been referred to therapy for help in dealing with her recent loss and assistance with the transition to independent living.

When Marian began therapy her statements were concrete and frequently tangential. The therapist soon discovered that Marian had an older sister who dominated her Iife and that she might be transferring her feelings for her sister to the therapist. Marian's therapy agenda was planned around encouraging this transference, then changing it to a trust relationship for the purpose of therapeutic work. Along with active transference, the therapist planned a program of assertive skills training which included guided fantasy, "I" statements, modeling and role-playing, and the affirmation of personal freełoms.

On a few occasions Marian accepted opportunities to express her grief in therapy. As the therapy progressed, she learned to assert herself in some instances and to experience and share some real emotion. When her new life style was threatened by her sister, Marian was in touch with and appropriately expressed her anger.

In the short space of eleven weeks Marian had not had time to resolve the conflict with her sister. The therapist recommended continued support during Marian's transition, probably by the apartment program managers at the Portland 
Habilitation Center. She would also need continued reassurance by her counselor that her feelings were valid and could be trusted.

A sex training course was recommended to give Marian the information she needed for relating to men friends. 
Richard was a 24 year old man with cerebral palsy who was described as being slow in thinking, talking and moving. Scores on a recent intelligence test, however, placed him high in the category of the borderline retarded on the verbal scale and within the range of the dull-normal on the performance scale. The test administrator had also suggested that Richard's potential might be greater than the scores had indicated. He was referred for therapy to make him aware of his potential, and to assist him in overcoming his slowness by providing opportunities to practice talking.

Transference was encouraged by determining Richard's need for confidentiality and by taking precautions to ensure his privacy. His reluctance to talk early in therapy was alleviated by a probe into its probable causes. As soon as he was able to find an appropriate word to fit his emotion, he relaxed considerably. The therapist further explored Richard's perception of mood and feeling through the use of pictures depicting people with a variety of facial expression. This led to a discussion of some subtler forms of human emotion.

When Richard was confronted during the course of therapy, he disclosed being aware of both the problem of his slowness and his level of intelligence. As the therapy progressed he was able to speak louder and longer, and with more animation and enthusiasm. He displayed a wider range of affect than he had during earlier sessions and was able to 
experience and express laughter and embarrassment in the present.

The therapist recommended continued practice in talking, with some intellectual stimulation to be provided by the staff at the Portland Habilitation Center. 
Name :

Age :

Date of birth:

Living arrangement:

Parents :

Siblings:

IQ, Full scale:

Verbal:

Performance:

Classification:

Medical diagnoses:

Medications :

Other tests:

Total sessions:

Duration:
Richard

June 7, 1953

Group home

Both living in Springfield, Oregon

Brother, Edward, 25

Brother, Ronald, 23

79

79

81

Borderline retardation

Cerebral palsy

None. Dr. Munter had recently recommended Elavil, an anxiety-reducing anti-depressant.

None

14

Twice a week for 6 weeks with one absence, then once a week for 3 weeks. 20 to 30 minutes plus one 60-minute field trip.

History. Richard's medical history revealed that he was born with ataxic type cerebral palsy and suspected brain damage. It was reported that he had slow thinking processes and that he performed tasks slowly. His perception of reality appeared distorted and he seemed to be detached from 
his surroundings. Prior examination by a physician revealed severe acne, exaggerated lumbar lordis, internal rotation of both knees, icy extremities and an ataxic gait.

A psychological report revealed a severe degree of retarded depression and a schizoid personality, with a probability of schizo-affective behavior. An additional evaluation described Richard as a slow, distractable young man who did not respond to praise. The report suggested there may be a problem with his mother's perception of him as inadequate, along with a poor self image and feelings of inadequacy.

In addition to the psychological interviews reported above, Richard had been in therapy at the portland Habilitation Center on two different occasions. He had two meetings with one therapist and attended sessions for two months with another therapist. Just prior to termination of that second series of meetings, the Wechsler Adult Intelligence Scale was administered. Richard's full scale I.Q. score was 79, which placed him high in the category of the borderline retarded. The test administrator's report suggested that Richard's intellectual potential was greater than the test scores indicated.

Richard was recommended for continued therapy based on his evaluation by that counselor. The selection committee for this thesis believed that, in light of this new information, it was thought that Richard could benefit from further counseling to overcome his slowness, to make him aware of his 
increased potential and perhaps to assist him in setting new goals for his future.

Richard had attended schools in special education and was a high school graduate.

Initial interview. During the initial interview the therapist explained the project and requested Richard's participation. Richard appeared very interested and asked appropriate questions about the planning and execution of a master's thesis. He was especially concerned about his privacy and was assured that his anonymity would be protected. The counselor agreed to show him all the case notes which were to be submitted to his file at the center and to use only his first name in the case report.

The informed consent form was read aloud and Richard signed it. He also requested a personal copy of his case report from the finished thesis. Richard was sophisticated in counseling so great care was taken to maintain continuity in his therapy. Transference was encouraged by determining his need for privacy in this setting and by the careful execution of precautions to insure that privacy.

To develop rapport at this initial interview, discussion centered on Richard's life away from the center. He said that he liked his group home and his house parents, that he liked to swim and go to the movies. He said his parents lived about a hundred miles from portland but they visited him on occasion and took him on trips, and he sometimes rode the bus to visit them. 
Richard spoke very slowly and softly. There was much hesitation between words but he was not difficult to understand. He smiled appropriately when he told a story about his workfloor and laughed as he recalled what he described as one of his supervisor's "stupid jokes."

First session. This session was a continuation of the initial interview. Richard talked about his friends and the group home but reported having no one special friend. He most enjoyed talking to and being with the male houseparent. Richard spoke so slowly it was difficult to discuss much in a single session. He reported being happy with his living situation and active on the weekends.

During this session the therapist questioned Richard about his slowness. He said he was aware of the condition but that it was not a problem for him.

The session lasted approximately 20 minutes.

Second session. Discussion centered about a planned trip to Richard's parents' home for a four-day Thanksgiving weekend. He appeared self-conscious about speaking. His voice was barely a whisper and he glanced frequently at the tape recorder. About twelve minutes into the session, the therapist addressed the issue. The following dialogue was taken from a transcript of that section.

T: You seem to be conscious of the tape recorder. Is it bothering you? C: [Pause]. No. No. 
$T$ : Are you curious about it?

C: Yes.

$\mathrm{T}$ : Would you like to hear yourself talk?

c: Yes.

T: I'll play some of it back.

I Recorder off.

$T$ : You said that you heard yourself on tape before.

C: Yeah.

$T$ : What did you think of it? When you heard yourself on tape?

C: Oh it sounded all right.

$T$ : While I was playing that tape back you said you didn't want to hear it and you said you were taking speech lessons. Are you taking speech lessons now?

c: When I go to class.

T: To Fran's?

c: Yeah, Fran's.

$\mathrm{T}$ : How are you doing?

C: Doing fine.

$\mathrm{T}$ : Are you self-conscious about speaking?

C: No.

$\mathrm{T}$ : I thought it might be something you're sensitive about.

C: No. No. 
T: It's not that?

C: No.

T: You're just curious?

C: Yeah. I had tape when I was in speech at school and I speak in school a lot.

T: Uh-huh. You speak softly. Do you always speak that softly, um, or is it just because of this little room?

C: It's because of this room.

T: When you're outside do you shout?

C: I could talk loud, yes.

T: You could?

C: Yes. I know that.

$T:$ What is it about this room that makes you want to whisper?

C: When I'm outside I can speak loud so that people can hear me.

T: Well I'd like to be able to hear you. Do you suppose you could speak a little louder when you talk to me?

c: Yeah. Yeah.

T: I'd appreciate that Richard.

The therapist changed the subject back to Richard's recent trip to the beach with his family and his impending visit to their home for the holidays. The theraplst probed into the nature of Richard's discussions with his family but 
could not elicit a response. Some examples were offered about what people might discuss with their families. Richard selected the Thanksgiving menu, television, and the football game as possible topics for conversation. Richard spoke noticably louder through the remainder of the session. Because of Richard's concern for privacy the therapist chose to leave the use of the tape recorder to the client's discretion during this stage of therapy when transference was being actively sought and a trusting relationship most crucial.

As a result of this precaution only one of the first five sessions was audio recorded while six of the last nine sessions were recorded and transcribed. In all, verbatim transcripts are available for seven of the fourteen sessions.

In addition, the therapist arranged to move the sessions to a larger meeting room to relieve some of Richard's apprehension about speaking out in therapy.

The session lasted 25 minutes.

Third session. The therapist's agenda for this session called for an exploration of Richard's fear of disclosure to the therapist and his denial of that fear. Richard could have been offering resistance to therapy because of this fear or it could have been something about the therapist he did not like. Since Richard had already been seen by a number of therapists, his apprehension could have been related to the previous therapist or to an observation that people come and 
go in his life so there was no point in becoming invested in another counselor.

These tactics effected a breakthrough in Richard's therapy. Use of the larger room afforded him some distance and turning off the tape recorder helped establish rapport. The therapist taught Richard the word "apprehension." Richard enjoyed the sound of the word, visibly relaxing as he repeated it a few times while nodding his approval. It was explained that apprehension feels like "holding yourself in" while exploring a new situation until it seemed okay to relax with people when you got to know them. Richard agreed that he was feeling apprehensive and seemed to appreciate having a word to associate with that feeling.

There was some evidence that transference was developing. Five minutes after leaving the session Richard returned to the counseling room to verify the fact that he remembered the therapist's name.

The session lasted 20 minutes.

Fourth session. Richard came to the session soaked with rain. Much of the session was spent drying his shoes and discussing the weather. Richard was encouraged to take the initiative in conversation. He was very talkative and took the lead on subjects which he felt were appropriate.

The session lasted 20 minutes.

Fifth session. As soon as the therapist met Richard at his work station he asserted his preference for the larger meeting room. 
The therapist's agenda called for a determination of Richard's perception of mood and feeling through the use of pictures of people with various facial expressions. His perceptions were accurate and realistic at the obvious level. The therapist led a discussion of some of the more subtle aspects of feeling happy, such as being excited, confident, silly, carefree, etc. The therapist briefly introduced the subject of personal involvement in some of these feelings of happiness and suggested they continue at the next session, along with the introduction of personal involvement in other emotions.

Examples of Richard's responses to the pictures follow. "She feels mad at something. She is crying like something hurt her. Could be tired. Other people are teasing or hurting. Saying something they are not supposed to say to you."

"He looks like his is frightened or scared. He saw something. Something made him frightened or scared. It could be anything. I don't know."

"Sad because her parents might have scolded her because she did something wrong. Punishing her for something she did. She could have disobeyed."

"He is happy because he might have just won a baseball game. That's why he is happy."

"He is in high school. He is smiling too. He has a book on his head. Like the guys and girls do that -- 
walk with the books on his head. Feeling happy."

The session lasted 25 minutes.

Sixth session. The therapist received Richard's permission to start taping the sessions again provided he remain in charge of the on/off switch. Before we could proceed, Richard requested another complete explanation of the thesis project. He required reassurance that confidentiality and anonymity would be protected. Richard appeared interested in the project. He asked appropriate questions and requested feedback on the outcome of the study.

The session lasted 25 minutes.

Seventh session. The agenda called for playing the "Ungame." Richard's responses were correct, appropriate, and concrete. Personal involvement was appropriate where indicated. None of the responses triggered any meaningful associations. The following bits of dialogue were taken from a transcript of the taped session.

Card: What will you have in ten years?

C: Lots of money.

T: Hm. Do you think you'll do it?

C: Yes.

Card: How do you act when you're angry?

C: I go home. I get mad and I want to beat someone up.

T: Does your body get all tense? You feel yourself tightering up?

C: Yep. Yes it does. 
The Ungame created an atmosphere of camaraderie through mutual disclosure and shared laughter over common likes, dislikes, and personal foibles:

T: Do your own thing. I hatethese things.

C: I hate them too.

T: They don't tell you what to do. You have to think. Richard continued to speak slowly but his speech was louder and with less hesitation.

The session lasted 25 minutes.

Eighth session. Since Richard continued to insist that his slowness was not a problem for him, the agenda for this session called for a field trip to a local restaurant where the therapist could observe his behavior away from the artificial setting of the counseling room. Except for a slight clumsiness in lifting his feet, Richard appeared well-adapted for community mobility. His speech was slow and soft most of the time but it became louder and more rapid when he spoke of something that interested him. He responded to comments appropriately and he initiated discussion about half the time. His eye contact was appropriate. Affect was varied and appropriate to the situation. Richard showed a fine, subtle sense of humor and a keen awareness of his surroundings. The field trip lasted approximately 60 minuies. Nintr session. The large room was not available so the session was held in the small counseling room. The therapist checked with Richard to be sure he was comfortable with the 
arrangement before proceeding. During this session the therapist concentrated on speaking less and allowing Richard time to talk more. Richard was capable of making a statement and then elaborating in some detail.

T: What did you get for a present?

C: Brut 33 shave lotion, after shave lotion. I got that and...Xavier's news, news almanac. A big book. Of all different things of 197-, I think it's of 1977 .

T: Is it stuff you'll be able to use?

c: Yeah, Yeah. Lots to read. It's a big book. Lots of pages. Some colored maps. All the things you know or want to know through history that's in 1977, the past year. I got that from Tom --, a counselor. He bought it at Fred Meyers.

T: That was real thoughtful of Tom, wasn't it?

c: Yeah. I needed it too. To have it. Then we had a party. We had punch and cookies. We had cupcakes and fudge. And that's all.

The above exchange lasted two minutes and 50 seconds. Richard continued to speak slowly but he spoke louder and more enthusiastically than in the past. The small room and the presence of the tape recorder did not appear to be distressing him.

The session lasted approximately 20 minutes. 
Tenth session. Richard continued to progress in being able to carry on a clear, correct, and intelligent conversaticn. He verbalized for several minutes at a time with minimal encouragement such as a brief question, comment, or uh-huh response. About six minutes into the session the counselor confronted Richard with the fact that he was brighter than most of his coworkers and fellow students. Richard said he had been aware of the situation. The remainder of the session was spent in exploring ways in which Richard could stimulate and extend himself intellectually, especially by spending time with staff and higher-ability clients at the Center and with normally intelligent people away from the Center. He reported going to rock concerts, movies or taverns on the weekends. In fact, he proudly stated that he could go anywhere he wanted on the weekends. He said he often spent time with his girl friend or with other people. Since his group parent, Tom, was leaving for another state, Richard said he was looking forward to making friends with his new house parent.

From his self-report to the therapist, Richard appeared motivated and aware. He reported being aware of and working on his pilysical slowness and suggested that he was capable of handling his life. Richard planned to join the food service program as soon as his work speed was acceptable and to continue speech lessons at the Center.

The session lasted 20 minutes. 
Eleventh session. The agenda at this point was simply to provide intellectual stimulation and opportunities for Richard to practice conversational skills. At this session Richard chose films as a topic for discussion.

In contrast to earlier reports, Richard's self-esteem at this session appeared quite good. He reported living up to his own expectations of himself. He had set goals for himself to increase production and was meeting those goals. He appeared proud of his ability to provide amusement for himself away from the center, and to spend time with friends. The session lasted 25 minutes.

Twelfth session. The meeting was held in a small office because neither the counseling room nor the large meeting room was available. A ringing telephone interrupted the discussion three different times during the session. Richard talked less than usual but he held up his end of the discussion despite the cramped quarters. He hold about his holiday bus trip in an ice storm and how they were delayed three hours while the driver installed chains. Richard reported remaining calm, confident they would get back to Portland. The therapist praised him for his patience during the ordeal.

In terms of New Year's resolutions, Richard said he was going to try to work harder and faster in the workshop. About fourteen minutes into the session the therapist questioned him about his progress and complimented him on 
his accomplishment. Richard responded appropriately to the praise.

C: I'm doing pretty good.

$\mathrm{T}$ : Are you improving in the workshop?

C: Yes.

T: That's good. I've noticed that you've changed a lot since we first met. You seem to be more relaxed. Are you feeling more relaxed?

C: Yes.

$\mathrm{T}$ : And you seem more sure of yourself. More of what the kids call "together." Are you feeling confident?

C: Yeah. I am.

$\mathrm{T}$ : It shows in your personality, in the way you look and the way you behave. $\angle \bar{P}$ ause $\bar{T}$.

T: That pleases you!

C: Yes. It does.

T: You look a little pleased and a little confused.

C: It does please me. It makes me happy.

The session lasted 20 minutes.

Thirteenth session. Richard insisted on meeting in the larger room. Discussion centered on leisure time activities, especially dancing. Richard expressed some real emotion including slight embarrassment and genuine laughter.

$T$ : How do people dance nowadays? Is it together or apart? What are some of the new things? 
C: Kids go to dances and sometimes they dance apart and sometimes they dance together. Close together.

$\mathrm{T}$ : Anything goes then? You can pretty much do what you want.

C: Yeah. Ha ha.

T: What's funny about that? What's tickling you?

C: That they dance, ha ha.

T: They dance what? You're laughing so hard you can't talk. That they dance what?

C: They dance good. Yeah. I like it myself.

T: You do.

C: Yeah. Ha ha.

$T$ : What do you like about it?

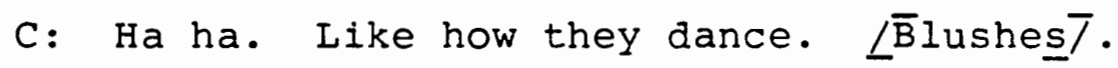

T: You like the feel of another person close to you?

C: Uh, yeah.

T: I do too. LIater $\bar{T}$.

$\mathrm{T}$ : It makes it easier to talk.

C: No, you talk after you dance. Dance, then talk. $\angle \bar{B}$ oth laugh $\bar{T}$.

T: What do you talk about?

$C$ : Anything. Anything you want.

$\mathrm{T}$ : Are you good at making conversation?

C: Yeah. Yeah. I am. Yes. Talk about anything I want to talk about. I like to go to dances. I like to do other things. Go downtown. Walk around. 
T: Did you say knock around?

C: No! Walk around. No.

Richard was very talkative, relaxed and confident. There was a lot of laughter shared during the session. He looked : o: ward to the next session as arrangements were made for another meeting. He continued to show concern for his privacy, however, at one point when the therapist said she was meeting two people the following wednesday. The therapist quickly reassured him.

$T$ : I'll try to arrange it so I only see two people. That way I can spend more time with you.

C: What two people?

$T$ : You and one other person--not together!

C: One after: each other.

Apparently unwilling to leave, Richard spoke for a full four and a half minutes after the first attempt to terminate the session.

The session lasted 25 minutes.

Fourteenth session. The beginning of this termination session was spent in completing business and discussing the end of the therapeutic relationship. The therapist gave Richard positive feedback about his progress and praised him for talking more and talking louder. She said she would write a final recommendation for his records and asked him what he would like to see in the report. Richard said he wanted people to know he was easy to get along with, good to 
work with, and dependable. The therapist told him that his supervisors had reported they enjoyed working with him also. Richard had been coming to the meetings eagerly. The second half of the termination session was spent winding down as Richard talked about trips he had taken and gave a rather lengthy lecture on the joys of gambling in Reno and Lake Tahoe. He spoke animatedly, in loud clear tones, when he had something to say that interested him. Otherwise he reverted to whisper-like slow speech.

The session lasted 30 minutes.

Summary. Richard was a 24 year old man with cerebral palsy who was reported to be a slow thinker and a slow talker, with a poor self imate and feelings of inadequacy. A Wechsler Adult Intelligence Scale recently placed Richard at the high end of the borderline retardation category. He was recommended for therapy to make him aware of his increased potential and to assist him in overcoming his slowness and in setting future goals.

Discovering Richard's need for confidentiality and space, the therapist encouraged transference by manipulating the therapeutic environment to accommodate these needs. A larger room was used for the sessions and the recorder was not used until the client felt safe and comfortable. Early resistances were analyzed and alleviated through this same manipulation. Richard's degree of verbalizing appeared to be directly related to the size of the room. 
Richard was confronted with his slowness early in the therapy and claimed it was not a problem. He later admitted that he was working on the situation by trying to speed up his production in the work area.

He was later confronted with the fact of his relatively high WAIS scores. He said that he had been aware of the sitation and consequently sought higher-ability clients, staff, and house parents with whom to associate.

Richard was encouraged to get in touch with his feelings through the therapist's teaching him the names of different emotions to which he could relate, and discussing with him some of the subtler aspects of those emotions. Pictures were used as a further tool in prompting discussions about emotions.

As trust developed over time, Richard began to speak more animatedly and enthusiastically. Although his affect had always been appropriate, he began to show a wider range of emotions. He accepted praise graciously and appeared confident that he was, in fact, well throught of. Finally, he was able to share laughter and embarrassment with the therapist in the present.

In the final case notes for Richard's file, the therapist recommended continued intellectual stimulation and practice talking. Richard's program should include more interaction with the staff or a regular job in the office of the Portland Habilitation Center. 
This 21 year old woman was referred for therapy to assist her in suppressing acting-out behavior and to deal with her anger at being sterilized against her will.

Since the client had previously been terminated from therapy for lying, transference was encouraged in this instance by largely ignoring the content of her speech and focusing instead on her concerns as she presented them each session. She was also encouraged to share her fantasies in therapy .

The therapist consistently secured Cathy's permission to check the reality of situations she described and reported the results of her findings to Cathy.

Some assertiveness training techniques provided Cathy with opportunities to rehearse dialogue that she might be able to use with her house parents and with an aunt.

In many instances Cathy was able to express her emotions in the immediate moment. At other times, however, she accepted "bad" news too calmly.

Cathy was recommended for continued supportive therapy with frequent reality checks until she had acquired enough problem-solving skills to accept responsibility for her behavior. 


\section{Age:}

21

Date of birth:

November 24,1956

Living arrangement: Group home

Parents:

Siblings:

Both living; Divorced

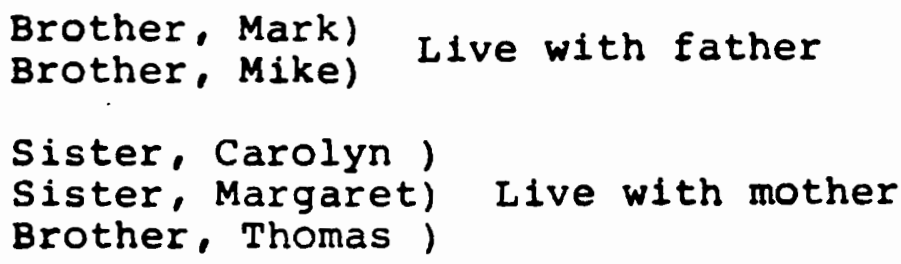

IQ, Full scale: $\quad 54$

Verbal: $\quad 63$

Performance: $\quad 51$

Classification: Mild/Moderate retardation

Medical diagnosis: Epilepsy, controlled petit mal seizures Medications: $\quad$ Phenobarbitol, $60 \mathrm{mg} 3 \times /$ day

Other tests: None

Total sessions: $\quad 15$

Twice a week for 6 weeks with one absence, then once a week for 4 weeks

Duration: $\quad 10$ to 32 minutes

History. Cathy was a 21 year old female who had been admitted to the Fairview school at the age of 3 . She attended Emily School and Center School before being admitted to the Portland Habilitation Center. In addition, she had completed sex education courses at Portland State University and at the Portland Habilitation Center. 
Medical history revealed that Cathy's mother had an uneventful pregnancy and normal delivery. Cathy's early history was normal until the age of 4-5 months when petit mal seizures began. Medical examination also reported a suspicion of neurofibromatosis. The seizures were under control with a daily dosage of phenobarbitol. At her mother's insistence, Cathy underwent a hysterectomy as a sterilization procedure three months prior to the beginning of this project.

Cathy's parents were divorced. Two of her brothers Iived with their father while two sisters and a third brother lived with their mother. Cathy lived in a group home from which she occasionally ran away.

Cathy's records described her as having good social skills but flat affect. Her behavior was reported to be immature and childish. She had a history of sexual relations with a large number of men. Cathy had had a few sessions with a previous therapist a year earlier but they were terminated because she was found to have lied consistently to the therapist. Cathy was recommended for therapy because she had recently been sterilized against her will. It was believed that further counseling could help her to deal with the physical and emotional post-surgical trauma and to perhaps assist her in overcoming some of her acting-out behavior. Initial interview. During the initial interview the therapist explained the project and requested Cathy's participation. The informed consent form was read aloud and 
the client signed it. To develop rapport a directed discussion centered on Cathy's friends at the center, her family, and her life at the group home.

Cathy reported having a boyfriend, Roger, who was also a client at the center. She said that another client, Jodi, "fooled around" with Roger and that she had had to tell her to leave him alone. She said her mother lived "down the street" and her father was "around somewhere." Cathy reported being very unhappy with the group home in which she was living.

Cathy appeared eager to talk but had difficulty saying what she meant. She frequently contradicted herself. Her voice range was within normal limits and she expressed emotion appropriately but there was little facial expression and her posture was slumped.

First session. Since the topic of this thesis involved short-term supportive therapy, the therapist chose to ignore any suspicion that cathy might be lying and to focus the agenda largely on her concerns as they surfaced from session to session. At the same time it was believed important to consistently verify the reality of Cathy's perceptions so that she could be helped to deal with these issues in a realistic manner.

During this initial session Cathy's concern was with smoking since it was national "no smoking day" and the clients at the Center had just been exposed to a film on lung 
cancer. Cathy reported that Roger broke up with her the previous Friday because he claimed she tied him down. Then she said that she quit smoking and wanted Roger to cut down also.

The session lasted 13 minutes.

second session. The discussion continued to focus on Cathy's relationships with the young men at the center. She said she received a ring from her friend, David, the previous Friday (the same day that Roger broke up with her) but that she still wanted Roger to be her boyfriend.

Since Cathy was sophisticated in therapy, the therapist felt it important to foster transference as early as posisible. Cathy was therefore given permission to fantasize an ideal life for herself in the future. During the fantasy she addresised the issue of her recent sterilization by making up a story about living on a cattle ranch in Californis with Roger as her husband and with their adopted blond daughter. The session lasted 12 minutes.

Third session. The session began with a continued discussion of the Roger-Cathy-David triad. Cathy said that she preferred Roger but also wanted to wear David's ring. She said that she and Roger were like brother and sister ("full blooded Cherokee blood brothers"). Then she contradicted herself by saying that Roger liked sex with her but David did not and she did not know what David wanted. The 
therapist suggested she confront David to ascertain his expectations of her.

Cathy was very excited about a weekend trip to the beach for the Thanksgiving holiday during which her family surprised her with a party and presents to celebrate her twenty-first birthday.

The session lasted 10 minutes.

Fourth session. The main theme of Cathy's therapy continued to center on her relationships, especially with young men. To help Cathy communicate her perception of these relationships she was asked to illustrate her ideas with a diagram. Three new people showed up on the diagram but there was no mention of David. Nadine was coupled with Garth, Sandy was paired with Roger, and Cathy was placed as a friend to both Roger and Garth. Cathy's diagram is shown below. Cathy reported that she still had strong feelings
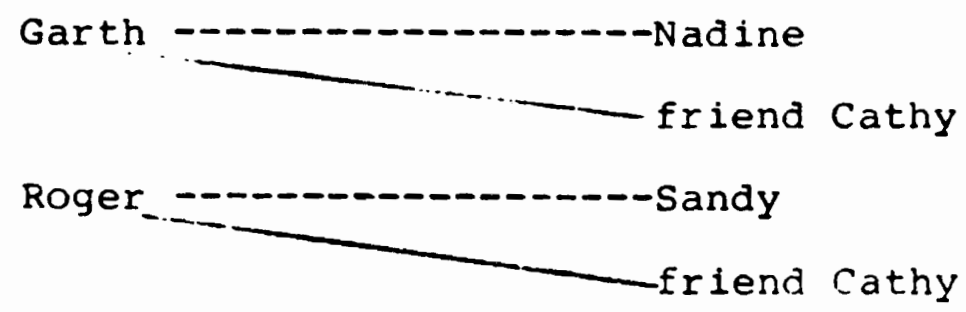

for Roger and that she wanted to get back with him.

To determine the reality of the client's expectations, the therapist asked for and received Cathy's permission to interview Roger on her behalf. Roger reported to the therapist that reconciliation was impossible because he was already involved in a relationship with sandy. It was his 
further opinion that Cathy was a "hooker" who had been involved with many men but that she had a problem maintaining relationships because of immature behavior, specifically poking, hitting and nagging.

Roger reported trying to help Cathy by "playing psychiatrist." He said that she was difficult and challenging to work with and that she needed a lot of love, especially from her parents. He said he believed that Cathy lost his baby during her recent hysterectomy and that was perhaps the reason she still felt so attached to him.

The session lasted 15 minutes. The interview with Roger was approximately 10 minutes long.

Fifth session. The therapist confronted Cathy with the fact that Roger reported being seriously involved with another woman. Cathy accepted the news calmly. She cleared her throat a few times then said it was okay because they would always be Cherokee blood brothers anyway. Roger had mentioned to the therapist during their interview that he and Garth were like brothers but he had not included Cathy as part of that relationship.

Cathy reported being involved with a new man, Mike, whom she had met on the bus and who had taken her to dinner and bowling the previous Saturday. She said that Mike worked in a downtown hotel and that he had been meeting her at the bus stop and escorting her to the center.

The session lasted 13 minutes. 
Sixth session. The therapist's agenda for this session involved an exploration of Cathy's immature behavior in relating to men. Discussion involved some of the things she did with Rober that caused him to reject her. Cathy reported being aware of the impact of her poking, hitting and nagging on a relationship. She said that she was feeling more confident than she had in a long time and that she was pleased with the way Mike treated her.

The session lasted 15 minutes.

Seventh session. Cathy was upset about an incident which occurred the evening before at the group home. A male client had entered her bedroom which she was undressed in preparation for her bath. One of the house parents became angry and swore at Cathy. Throughout the session Cathy was in touch with her own anger and expressed it appropriately, through shouting, as she related the incident.

Cathy was still very difficult to understand. She did not seem to be aware of the fact that her speech was fragmented and she behaved as though she was explaining clearly. The therapist had to ask many questions in order to piece Cathy's story together while Cathy showed annoyance at the therapist's inability to comprehend. About seventeen minutes into the session, the incident finally became clear.

C: I start crying about that part. Like somebody's mixed my head. I can't think any more. They screwed it up last night.

$T$ : You were upset so you can't think straight today. 
c: I told Virgil "you can't go in that room." I said "I'm sorry you can't come in." I shut the door.

$T$ : What was he doing in your room?

C: Being says you care for me and Debbie says "What the hell's going on up here?"

$\mathrm{T}$ : Were you dressed when he came in?

C: No.

$T$ : Is that what upset you--and Debbie?

C: Yeah. Debbie came up to see what's going on. I said "I'm waiting for Brad. He's taking so long" [in his bath]. I told her right in front of Virgil "Don't go in my room. I'm not there." I told him, told him, "stay out of my place [unintelligible]."

$T$ : So you couldn't get virgil out of your room and Debbie was upset because you weren't dressed?

C: Right.

During the session Cathy said she wanted a direct confrontation with Debbie. The therapist praised Cathy for her adult approach to the problem and offered to role-play the part of Debbie as well as to summarize and clarify feelings for her.

T: Pretend I'm Debbie and tell me what you want to say to her. 
C: That's very difficult but I'll try it anyway. Debbie, a woman-to-woman talk. What's going on? or something like that. Why you pushing me? Your cue to say something.

$\mathrm{T}$ : It's my cue. [Pause]. I'm having a hard time responding because I don't know Debbie and I don't know what she would say but I wonder if you can tell Debbie how it is that you're feeling.

C: I feel rotten inside. It's pushing. Iike, I don't know how to say it, slavery. Pushing the slave. [later].

C: Tell me to take a bath, the next you want me to go downstairs. What else do you want me to do, not to do?

T: I'm hearing you say that you want some clear guidelines. You could say "I'm confused. I don't know what you want."

The session lasted 21 minutes.

Eighth session. Cathy's concern at this session involved an impending move to a new group home. The move appeared to be a mutual decision between herself, her guardians, and the group home managers. Cathy said she was pleased about leaving but was annoyed because she had no information about the new group home. 
During the rest of the session Cathy talked about having been baptized the previous sunday. She said it made her feel a part of something that had her feeling good inside. She had apparently been given some responsibility for refreshments and child care at the church and had been made to feel welcome by the pastor's family.

Cathy appeared calm and serious. She smiled appropriately when she described an eggnog with whipped cream they had served at church. Her eye contact was good, as usual. The session lasted 18 minutes.

Ninth session. During this session Cathy spoke of the approaching holiday. She was looking forward to Christmas and was excited about spending time with her family, especialIy her father whom she described as "special." She sighed as she spoke quietly of seeing him again.

Cathy had shopped very carefully for gifts and appeared happy as she described her purchases. Client and therapist laughed at her comical reminiscences of gift wrapping and the confusion of Christmas tree trimming.

Cathy said she had not seen Mike for awhile because he was working a night shift and needed his rest.

The session lasted 12 minutes.

Tenth session. The session began with Cathy enthusiastically telling of her visit with her father, of having dinner with her brothers and sisters at her mother's house, and of visiting with friends. She appeared excited and happy, 
laughing as she described their exchange of gifts.

Nine minutes into the session, the therapist asked about her plans to move and was told that Cathy's social worker was looking for a new group home for her. Between sessions the therapist had discussed the matter with her supervisor and had verified the fact that Cathy's group home was losing clients because of management problems. Cathy told about her frustration in being unable to talk with her house parents then drifted into a fantasy about living with her father and learning to drive his car.

About sixteen minutes into the session Cathy related a very confusing story about a death in the family. After three minutes of discussion the facts were still unclear.

$\mathrm{T}$ : When did he die?

C: Christmas Eve.

T: No wonder your grandmother was upset.

C: My aunt. Not my grandmother. No my aunt.

$\mathrm{T}$ : Let me see. You lost me somewhere. [Pause]. Who died?

C: My Aunt Edith's, not her husband but her grandfather.

The therapist was unable to determine Cathy's relationship to the deceased but it was clear that Cathy was upset because she had been told of the death "at the last minute" and because she had not been invited to the funeral which was to take place that day. The therapist suggested to Cathy 
that she deal with the reality of feeling left out by calling her mother, getting permission to leave the center early, and making arrangements for a relative to drive her to the funeral, if that was what she wanted to do.

The session lasted 25 minutes.

Eleventh session. During most of the session Cathy talked about death and funerals. She had been unable to 1ocate her mother to arrange for transportation to the funeral earlier in the week. She reported feeling sad, lonely and "terrible inside" at the loss of a family member and at being excluded from the funeral plans.

The therapist asked Cathy to make a plan for herself to deal with those feelings. She said she wanted to buy a few roses and to visit the gravesite. She also said that she would call on her aunt to express her sympathy and to let her know that she, too, needed to grieve. The therapist agreed that it was a good plan and explained the concept of closure. Cathy spent 15 minutes of the session in ruminating about her family.

Cathy reported that she was still seeing Mike and that they were getting along all right but she did not want to divert her attention away from family matters at the moment. She said she planned to contact her mother and her aunt during the weekend.

The session lasted 19 minutes.

Twelfth session. It had been a week and a half since the last session. Cathy told of running away from the group 
home because she found the place intolerable. Her house parent called the police who found her at David's apartment and drove her back to the group home. She described the experience as "weird" because they treated her "like a criminal" and would not believe that she was 21 years old. She also spoke of her feeling of abandonment by both Mike and David, who apparently had other girlfriends already, and of her frustration at not finding a new group home yet. Cathy was visibly upset and close to tears throughout the interview. The therapist let her know that she had been worried about her during her absence and offered to become her advocate in assisting with the search for a new home by contacting her house parent and her social worker in Cathy's behalf. Cathy was also given the therapist's home telephone number and was invited to call if she felt the situation at the group home was again becoming unbearable.

The session lasted 24 minutes.

Thirteenth session. Cathy began the session by informing the therapist that she was planning to marry Dave in February and that she was upset because other men were still after her. The therapist questioned Cathy further to determine whether or not she was aware of the consequences of her own behavior and of how she affected the men around her.

C: All the guys are after me. Don't know why. T: I think you do know why.

C: Well actually. The guys here are strange but who knows. My mom wants me to get married. 
[Later].

$T$ : How do you think Dave feels when these other guys are after you?

C: Dave gets mad when the guys want sex and want me to go to their house. I go uh uh.

T: You're a popular woman because you like sex, you know that, and they probably know it too.

C: But they don't know I'm getting married. Have to turn them down.

T: So if you and Dave have plans you have to let the other guys know you're not available.

Thirteen minutes into the session the subject was changed to Cathy's living arrangement. The therapist reported the results of a telephone conversation with Cathy's group parent during which she was informed that Cathy would be given "one more chance" to remain at the group home and that her mother was applying for guardianship so that she could become involved if Cathy ran away again. Cathy said she knew of the guardianship but had not been told about the decision to keep her at the group home. Cathy took the news calmly once again, remarking only that it was okay because she already knew the bus route.

Cathy shifted the subject back to her relationships with men and launched into a lengthy monologue about how difficult it was to have so many men wanting her. Cathy had apparently been propositoned at the center, on the street, 
and at church. She mentioned her embarrassment at having to deal with such a situation in front of her pastor.

The session lasted 32 minutes. Eighteen minutes of that time was used by Cathy in reminating about her difficulties in being pursued by many men. Throughout the session her mood was serious and her face expressionless although her voice range was appropriate in terms of volume and inflection.

Fourteenth session. Cathy was in a serious mood as the session began. Roger had just told her that David had a new girlfiend which rather upset her plans for marriage. She also said that David had a gun and planned to kill her. Nevertheless Cathy was pleased because Roger was going to protect her and that meant they would have to spend some time together. Cathy had not checked the story with David but was willing to accept Roger's version. Instead, she was angry with David for lying to her and was looking forward to sitting with Roger at lunch.

Cathy sat in a relaxed position with her feet on an open desk drawer and spoke in a childlike, occasionally singsong voice about being protected by Roger and Garth, her "blood brothers." She would not entertain the idea that perhaps Roger had lied to her about David and would not accept the suggestion that she confront David directly.

The session lasted 20 minutes.

Fifteenth session. Most of the termination session was spent in Cathy's dissertation of religion and morality appar- 
ently precipitated by David's being caught stealing. Cathy said she confronted him in front of witnesses and told him he had to stop stealing.

The rest of the session was spent in reviewing and summarizing events of the past few weeks and advising Cathy on how to contact resource persons if she had further difficulty.

The session lasted 20 minutes.

Summary. Cathy was a 21 year old woman with a history of sexual relations with a large number of men. She had recently been sterilized against her wishes. She had been reco:mended for continued therapy to ease the physical and emotional post-surgical trauma and to help her overcome some acting-out behaviors.

The therapist selected a plan of supportive therapy that largely ignored the content of the client's alleged 1ying and concentrated on her concerns as she related them from session to session. A directed discussion was used to develop rapport and transference was encouraged by giving the client permission to fantasize. In addition, the therapist monitored the reality of the client's life situations and assisted her in arriving at realistic methods to deal with these situations. One reality check involved an interview with another client about the prospect of a lover's reconciliation. Another checked on the problems at the client's group home. Other reality checks involved confrontation with the client about 
the impact of her immature behavior on relationships with men (during session six) and the impact on men of her sexuality (during session thirteen).

Cathy was also taught to use the direct confrontation method in sharing her grief with an aunt over the death of a relative and in questioning her house parent about guidelines and expectations. The therapist encouraged Cathy to share her feelings by use of a role-playing/rehearsal model. When Cathy's acting-out behavior appeared to place her in some real danger, the therapist assumed the role of social worker and advocate to get the information the client needed but was unable to find out for herself.

Cathy seemed to be in touch with her feelings on a day to day basis and had no difficulty in sharing those feelings, although it was frequently difficult for her to communicate content. Her voice expressed fear, sorrow, joy, etc. as she experienced them. Although her face was largely expressionless and her posture generally listless, Cathy's voice range and inflection were appropriate.

In the therapist's final notes, Cathy was recommended for continued supportive therapy. Because of her strange mixture of fantasy and reality, a good relationship with a counselor would need to be established. Once this was accomplished, reality therapy could be implemented along with support until she had developed enough skills in problem solving to be able to arrive at concrete insights. 
These insights are necessary to help her see the cause-andeffect relationship of her behavior. With the help of continued counseling it was believed she would make good progress toward assuming control over and responsibility for her own behavior. 
This was a case of a 37 year old man who was referred for therapy because of bashfilness, an inability to relate to people.

The therapist encouraged transference through a technique for increasing the self-esteem of the client by focusing attention on his accomplishments, specifically his knowledge of fish and animals. The transference was completed when Ray became aware of the therapist's absence at one point and eventually addressed the issue in session.

$\mathrm{H}$ is resistance to therapy was evident by fidgiting behavior. The therapist helped alleviate his discomfort at first by ending the sessions but, later in therapy, persisted in focusing on the behavior until he could assume control within the session.

An assertive technique employed the use of "I" statements as a tool for focusing on the self as narrator.

The client was encouraged to reveal his perception through the method of drawing pictures of people and animals. Ray's awareness of people was not pursued when it became evident that the task would not be accomplished within the short space of working time this thesis permitted. He did, however, respond to an increased awareness, in some limited sense by requesting bus training and was supported in his request by the therapist's assistance in formulating a plan and securing his mother's participation in the project.

The therapist recommended continued metro-mobility training for Ray's continued progress. 
Age : 36

Date of birth:

July 18,1941

Living arrangement: With parents

Parent:

Mother, housewife

Father, retired

Siblings:

Brother, George

IQ, Full scale:

55

Verbal:

53

Performance:

63

Classification:

Mild retardation

Medical diagnoses:

Diabetes

Arthritis

Obesity

Medications:

Orinase/Dymclar

Other tests:

Bender-Gestalt

Children's Thematic Apperception Test

Total sessions:

14

Twice a week for 6 weeks with one absence, then once a week for 3 weeks

Duration:

13 to 28 minutes plus one 58-minute test session and one 60-minute field trip.

History. Ray was described as friendly but slow and deliberate both physically and cognitively. His records showed a report of a Bender-Gestalt test indicating evidence of organic involvement. There was no social background or early history avallable. Ray attended schools of special education through the age of 16 and was referred to the 
Portland Habilitation Center in May 1973 at the age of 31 .

He was recommended for therapy because of bashfulness. Ray was fond of animals but did not relate well to people. He did not talk much. Ray was in a weight-loss group to curtail his obesity and it was believed that concurrent therapy would help to increase his self-esteem and body awareness as well as his consciousness of and contact with other human beings.

Initial interview. During the initia? interview the therapist explained the project to Ray and asked for his participation. They read the informed consent form together and Ray signed it. Rapport was established by chatting about Ray's home life, his stay at the Center, and his dog, Tillie. Ray also discussed his brother, George, who apparently lived away from his parents' house and worked in an art studio.

Ray's eye contact was appropriate but he smiled throughout the entire session. He spoke in a quiet monotone. His responses were limited to a few words or a phrase. The interview took the form of a question-and-answer session. Ray seldom volunteered information.

First session. The session began with a directed discussion but quickly deteriorated into the question-andanswer format. The therapist would occasionally use a leading statement or "uh-huh" response to encourage Ray to talk. The content was mostly about Ray's favorite activities 
and about animals. Ray's associations were concrete. While the therapist tried to capture his involvement with the subject under discussion, Ray's responses remained non-personal. This is illustrated by the following dialogue taken from the transcript of that session.

$T$ : What do you like abrut them /the animals/?

C: They're little.

T: Uh-huh.

C: Get milk from mother.

T: What do you like about that?

C: The bucket.

T: What about the bucket?

C: You put the m-milk in there.

A little further into the interview the therapist attempted to get Ray to express some of his feelings about playing with his dog but again Ray's responses indicated he was not involved with the subject. About fifteen minutes into the session Ray found a topic that interested him enough to string four phrases together. The therapist was silent as Ray spoke, paused, and spoke again.

T: Tell me about your nieces.

C: Go to school. Then they come over weekends. Then we have hamburgers. At the Burger king.

Finally, the therapist focused on the present and elicited a here-and-now response from Ray.

T: You're getting fidgety. Are you restless?

C: No. 
T: Do you know what that means? Fidgaty? Restless?

C: No.

$T$ : When you twist in your chair like that. I think you would like to leave.

C: [İaughs].

$\mathrm{T}$ : Do you want to stay? Or do you want to leave?

C: Uh, leave.

Ray's nervous laugh suggested he was aware of the situation and his own discomfort. The therapist ended the session quickly to afford Ray the opportunity to resume his distance. This early in therapy transference was being encouraged. The therapist did not want the sessions to be aversive to the client. As therapy progressed, negative feelings would be allowed to surface and would be confronted and worked through. The first session lasted 18 minutes.

second session. The therapist's agenda for this session was to continue to encourage transference and to employ a technique for increasing the client's self esteem by stressing his accomplishments. As it happened, the cllent provided the tools for discussion as the theraplst listened to him display his knowledge of fish and animals. There was evidence that transference was taking place because Ray brought a book about fish to the session. In this way he not only took charge by establishing his own agenda, he also brought evidence to indicate that he had looked forward to 
or at least had given some thought to attending the meeting. Client and therapist spent most of the session looking at pictures of fish together. Discussion centered on the different kinds of fish, especially their colors. Ray seemed to respond emotionally to color. He said he liked the goldfish because they were pretty but he disliked the black fish. He also said that one of his favorite pastimes at home was to color pictures of animals in coloring books, being careful to make them the color they are supposed to be. $\mathrm{T}$ : He's an odd looking one, isn't he?

C: Yeah. Oh. Matches his look about stuff in a bowl. Sort of green and sand.

T: Oh. So you think he fits right into his background. C: Iike this one here.

They also talked about animals at the $z 00$ and OMSI while they were looking at the pictures. As in the first session, Ray reported looking at the animals but never touching, not even at those exhibits designed for petting the animals. Since Ray had selected a subject which obviously interested him, he began to volunteer information and, at one point, to speak in a complete sentence.

T: What do you look at when you go to OMSI?

C: Chicks. Baby chickens. That grows up and comes out of $a$ hen and rooster. Female chicken lays eggs and eat um.

Toward the end of the session, the therapist asked Ray about his ever-present smile. Ray said that he was a happy 
person and that he never got mad, unhappy, or sad. As soon as the discussion focused on Ray and his feelings, he started to fidgit and twist in his chair.

The session lasted 16 minutes.

Third session. The technique for this session employed a variation of a projective test to explore Ray's knowledge of facial expression and emotion. Ray looked at pictures of people from a magazine and told a story about what the person might be feeling. This technique was designed to draw Ray's attention away from animals and to begin focusing on human beings in general and eventually to himself as a person. The pictures were of people who could have been happy, sad or serious. Ray had no trouble identifying the happy and sad faces but he mistook a serious face for happy. The therapist explained facial cues as ways of telling how people feel.

Ray smiled most of the time, as usual. He looked serious at one point while he was thinking of a story. The therapist called attention to the serious expression so that Ray could experience the difference between serious and happy on his own face.

The session lasted 15 minutes.

Fourth session. The session was a continuation of session three. The therapist showed Ray more pictures while discussion centered around the emotions of anger and sadness. Fay was able to describe situations which might elicit these 
feelings but he denied ever feeling sad or angry himself except to become upset if he was teased or shoved.

The second half of the session shifted to the assertive training technique of practicing "I" statements. Ray was asked to tell stories about himself in the first person. This technique continued to focus on Ray as a person while allowing him to discuss an emotionally safe subject for him such as the weather and his visit to the doctor that morning.

The session lasted 18 minutes.

Fifth session. Ray came in to the counseling room talking about his trip to Albertson's that morning as part of his training in independent living. As soon as he sat down, the therapist asked him to retell the story. Ray started to tell the story as he had been telling it, then spontaneously shifted to a first-person narration. This was apparently difficult for him to maintain because he occasionally reverted to his habit of skipping pronouns. He did manage to begin sentences with "I" throughout most of the story. As discussion shifted to animals, Christmas and the news, the therapist encouraged him to continue his "I" statements.

C: See a tree up in the house.

$\mathrm{T}$ : Tell me that in a whole sentence.

C: I saw a Christmas tree up in the house.

Atolit fifteen minutes into the session the therapist shiftec to another technique as preparation for the next session. Ray was invited to express himself through drawing. 
He chose a bull moose for his subject. A copy of the drawing is attached (see page 114). Discussion of the drawing follows in session six.

The session lasted 20 minutes.

Sixth session. Ray brought tracing paper to the session, an indication that transference continued to develop inasmuch as he prepared himself for the meetings. The therapist's agenda called for continued artistic expression but with a focus on people as subjects. Ray showed a considerable amount of resistance to the project. He flipped through a number of sample pictures and selected a picture of a boy and girl holding a frog as the one he would like to copy. When he announced that the picture was completed, he had drawn only the frog. The therapist encouraged Ray to try to draw the little boy. When he had again completed his drawing, the following discussion ensued.

$\mathrm{T}$ : Tell me about your picture. Who is this?

C: Umm. Thelma.

$\mathrm{T}$ : Is that the little girl?

C: Umm. Yeah.

T: Are you happy with the way it turned out?

C : Umm.

The therapist had spent some time trying to get Ray to look carefully at the picture of the little girl he had drawn so that he could make any changes he felt were necessary. He seemed satisfied with it as it was. A copy of the drawings 


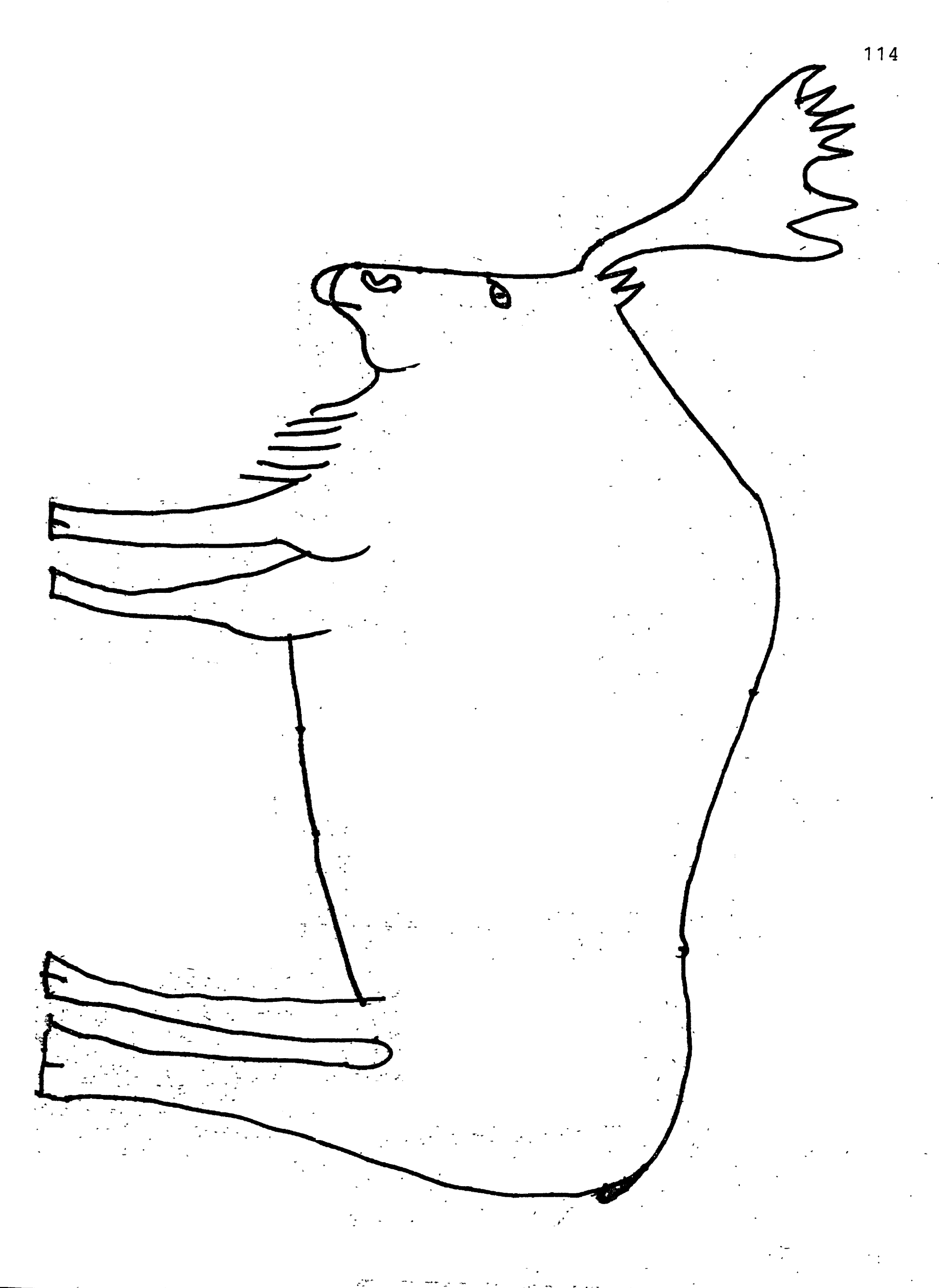


is attached (see page 116).

Ray's perception of animals was fairly accurate. The bullmoose's head, antlers, legs and tail were well proportioned to its body. Its eyes, nose and ears were accurately placed. Iikewise the frog's legs and head were proportioned to its body, the eyes large and mouth wide as in the sample picture. When it came to perceiving humans, however, Ray's interpretation bordered on the grotesque. Ray drew a male or sexless creature even though he described it as a little girl. It had large shoulders and no waist or hips. Its head was toc small for the body, and its ears stuck up and out like an animals'. The mouth was wide and full of teeth. Hair hung along the side of a bald-topped head.

When Ray appeared satisfied with his drawing, his attention was returned to the original picture and the story telling continued. The therapist pointed out the difference in expression between the boy and the girl, and the different ways in which they were handling the frog, suggesting that one was pleased with it while the other was reluctant to touch it. Ray said he thought the frog might feel slimy but that a slimy feeling was okay. The therapist began to call Ray's attention to items in the picture which could serve as clues in determining how people feel about what they are doing. For instance, the boy held the frog in two hands while the girl pointed a finger and barely touched it. 
116

little girl

frog
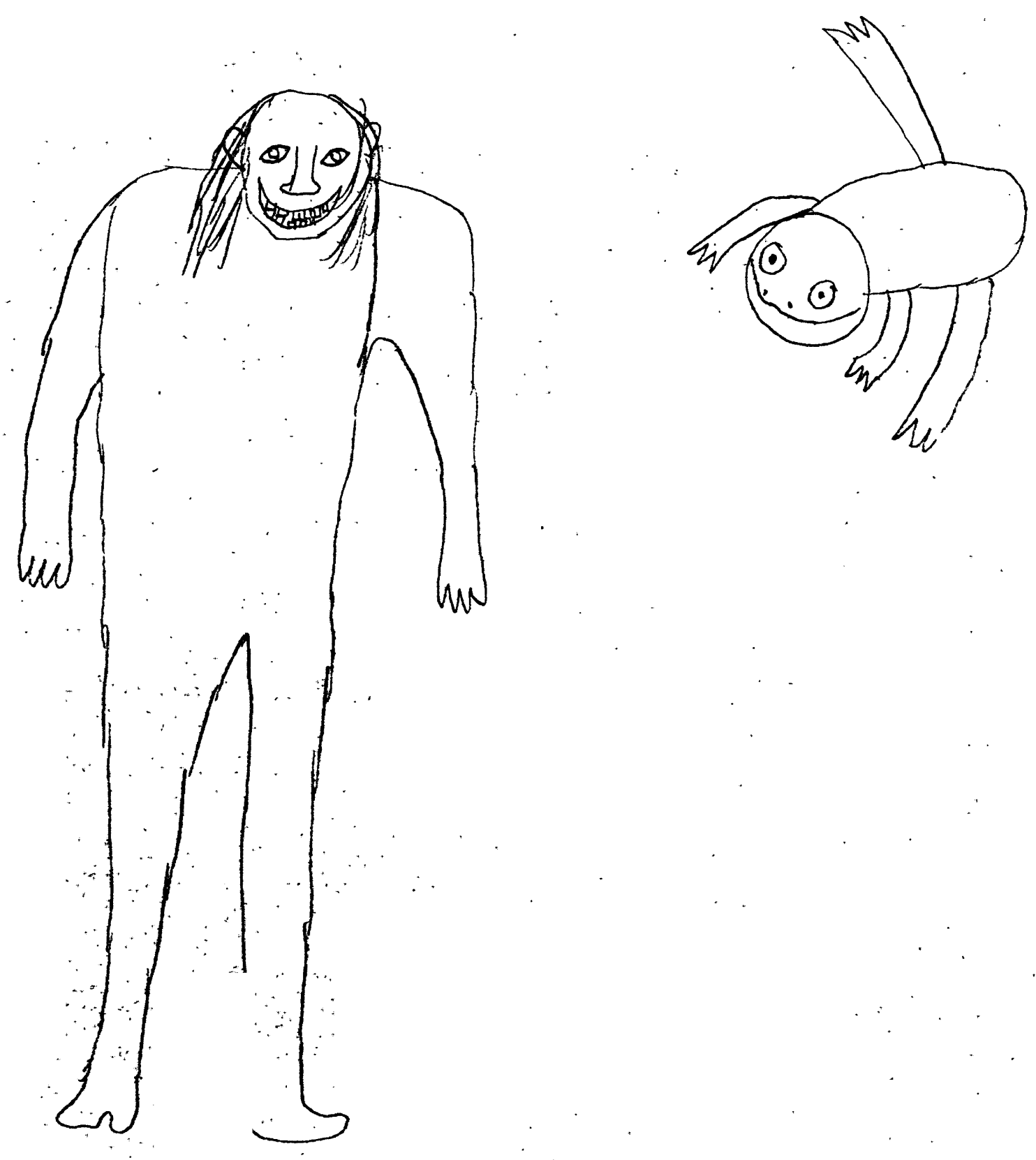
Near the end of the session the therapist, once again, centered the discussion on Ray's personal experience. As usual, Ray denied involvement with the emotions of fear or apprehension. With some prompting by the therapist, he confessed only to a sense of curiosity. Ray reported being cautious when he encountered new situations.

Transference was being encouraged through the use of Ray's artistic expression and appeared to be progressing inasmuch as he continued to show initiative by brirging some of his own materials to the session. When he showed resistance to drawing a person, he was permitted to start with a frog, then was encouraged to try to draw the little boy. He vas then offered instruction in spotting facial and body cues as indicative of human emotion.

The session lasted 28 minutes.

Seventh session. The first third of the session was designed to explore Ray's expression of emotion through color. The therapist presented Ray with a gift of fluorescent crayons in a further attempt to foster transference. Ray chose an octopus for his subject and complained that there was no brown crayon for the octopus. This was a typical response for Ray who was always careful to color his animal pictures the way they were supposed to be.

The rest of the session was devoted to playing the Ungame. Ray's responses were concrete and personally uninvolved, but correct and appropriate. He answered each question but did not free associate. 
The session lasted 20 minutes.

Eighth session. The therapist's agenda for this session was designed to provide the client with opportunities to practice talking, to relate to and communicate with a human being. Once again Ray had planned his own activities. He brought materials to show the therapist, he initiated three topics of conversation and asked three questions during the first five minutes of the session. The discussion was relatively lively. Both client and therapist were more talkative than usual.

Towards the end of the session when Ray started to fidget, the therapist called attention to his behavior. Ray informed her that it was two $0^{\prime}$ clock and time to take his break.

The session lasted 15 minutes.

Ninth session. This session was designed to further probe Ray's attitudes towards people. He offered no resistance to the suggestion that he draw a person. Four minutes after the start of the session he had what he believed was a picture of his brother, George. At this point the drawing consisted of a body outline and a nose (see light outline on page 119). With prompting he continued drawing, adding eyeglasses, other body parts, and clothing. As he drew, he became increasingly agitated. This was unusual because it was only seven minutes into the session and he usually started to fidget around the twelfth minute. 


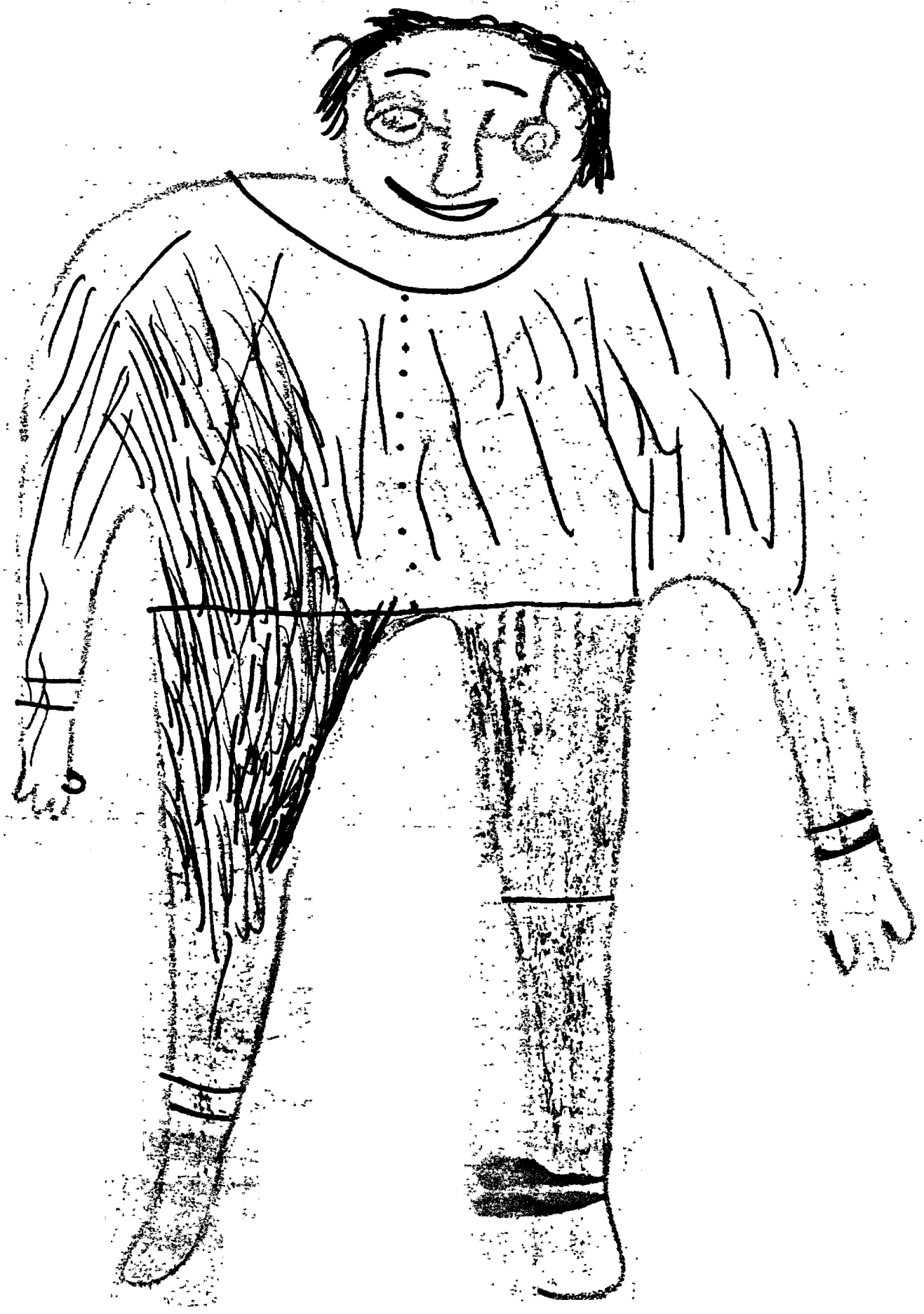


$T$ : Are you nervous? It's only 11:30, you don't go to lunch until twelve. You don't want to be here, do you?

\section{C: Sometimes, Yeah.}

While the client was obviously uncomfortable, the topic was pursued rather than aborted as in earlier sessions so he could regain control now by working through his feelings.

$T$ : What is it you don't like, Ray?

c: Nothing. Go to lunch. LIaughs T.

$T$ : It's not time for lunch. I hoped we could talk so I can understand how you are feeling.

The therapist asked Ray if it was the room, talking, the therapist or the tape recorder that he did not like. During this time Ray continued to scratch heavy, straight lines on his drawing with a red felt pen. He finally said he disliked the tape recorder "a little bit." The therapist explained the volume control, the on-off switch and the microphone. Control of the tape recorder was turned over to Ray so he could feel in control of himself and the situation, thereby relieving his discomfort before the session ended.

The session lasted 13 minutes.

Tenth session. The therapist began by turning control of the tape recorder over to Ray. He chose to leave it on. Ray was excited about the aquarium he just received as a Christmas gift. He said his mother would drive him to a nearby shopping center the following weekend to select the fish. He reported that he never went anywhere by himself 
because he might get lost. Since Ray was taking bus trips with one of the instructors at the center as part of his skill-training in independent living, the therapist questioned him about his community mobility and encouraged his enthusiasm over being able to visit a number of pet stores in the city if he learned to ride the bus.

The therapist agreed to help Ray get started by writing a note to his counselor suggesting they request a metromobility volunteer to teach Ray the system. Using his love of pets as a lure, the bus training would assist Ray in getting around in the community and among people with whom he could relate.

Ray had not fidgeted throughout the entire session, which lasted 15 minutes.

Eleventh session. The client was in control of the tape recorder and chose to leave it on.

Ray's counselor reported that she had requested a volunteer for metro-mobility training but that none was available. She said she would discuss it with Ray's mother to solicit her participation. During this session the therapist suggested that Ray ask his mother also. They practiced sentences he might use in approaching her to request cooperation. To assist Ray in understanding that he would not be immediately thrust into a difficult situation, therapist and client developed a step-by-step procedure that Ray and his mother could use in bus training. 
During this session the therapist requested longer sentences. Ray was willing to practice. He used complete sentences spontaneously when interested in a subject but still spoke mainly in monosyllables.

Toward the end of the session the therapist asked about his feelings. She did not probe further because the sessions were winding down in anticipation of termination. Ray reported feeling fine and appeared to be fine. He had not fidgeted during the last two sessions. The discussions were centering around a future activity Ray might find satisfying and away from the sujbect of people. It would have been inadvisable to start something at tris point that could not be finished in the next few weeks.

Support was further offered to the client by means of a gift. The therapist presented Ray with a picture of an octopus from a brochure describing undersea gardens.

The session lasted 17 minutes.

Twelfth session. The therapist further supported Ray's interest in animals by presenting him with a picture of a sea lion. They discussed the colors in the picture and sea lions in general.

In response to a question about his bus training, Ray said he forgot to discuss it with his mother but said he would ask her that evening. The remainder of discussion centered on Ray's favorite people at the center, his ambition to stay at the Center, his aquarium, and the weight watchers group of which he was a member. 
The session, which lasted 15 minutes, contained long stretches of silence. The therapy appeared to be at an impasse.

Thirteenth session. The session lasted much longer than usual while the therapist administered the children's Apperception Test, which is a projective test designed to probe the client's subconscious. The client is instructed to tell stories about others which presumably relate to himself. Since Ray was so fond of animals, the Children's Apperception Test was selected even though Ray was an adult and the test was designed for use with children. Ray's responses to the picture stories were brief, but they were concrete and appropriate.

During the telling of his stories, Ray frequently interrupted by making comments or by asking questions of and about the therapist, her car, her dog, etc. Finally he said,

C: You be here Thursday or Friday?

T: No. We changed terms at school. I'll come here on Monday and Wednesday. Okay?

It was nearly thirty-four minutes into the session but Ray was not fidgeting and said he wanted to stay. Between sessions eleven and twelve the school term and the therapist's schedule had changed. In addition, the sessions were cut back from twice to once a week in an effort to gradually reduce dependence on the therapist that might have developed since 
the therapy began. The therapist had discussed this schedule change with each of the other clients but Ray had been unavailable that day so he had not been informed. During

session twelve, described above as at impasse, Ray could have been feeling the effects of the schedule change and his lack of information about it so he closed himself off more than usual. Now that he had taken the initiative and cleared up the matter to his satisfaction he became a willing participant.

Transference had been completed. For the first time since the sessions started, Ray's behavior indicated an awareness of the therapist as a person. He asked direct questions about her and her personal life. He called her to task, in a sense for failing to inform him of her schedule change. Further, he made it clear by his behavior and his comments that he was enjoying the present session.

Towards the end of the session, the therapist asked Ray about his progress with "I" statements. He explained that he had learned to say only what was important and to say it fast because no one would take time to listen to him finish. He further explained that he usually walked away from people who told him to do something he didn't want to do but that he could not walk away from the therapy sessions so he stayed and, essentially, tried to ignore some of the instructions. This could account for his fidgeting when he could not ignore a task he considered unpleasant, such as drawing people or talking about his feelings. Since there were only a few 
sessions left and since Ray had just learned he could express some control over his therapy in overt ways, the agenda for the next session was left for him to plan.

The session lasted 58 minutes.

Fourteenth session. During this session the client and therapist took a walk together. Ray had planned a somewhat ambitious eight block trek to a shopping plaza where he introduced the therapist to the activity of fish-watching. During the walk, they talked about animals and the weather.

The round-trip lasted about an hour.

This session turned out to be the final meeting because severe weather forced cancellation of the termination session. The therapist met briefly with Ray in an informal setting at the Center and spent a few minutes wrapping up loose ends. Since there was no unfinished business between them, it was not necessary to schedule any make-up sessions.

Summary. Ray had been recommended for therapy because of bashfulness. He was reported to be fond of animals but did not relate well to people and did not talk much. It was believed that therapy, occuring concurrently with attendance in a weight-loss group, would help Ray to increase his selfesteem and body awareness along with this consciousness of and contact with other human beings.

During the course of therapy it was found that Ray did not talk much because he spoke slowly. He felt he had to get the most important words said because most people would not take time to listen to him finish. He omitted pronouns and 
otler extraneous parts of speech except in those situations where he was excited about a subject or when someone took time to listen to him finish his thought. Ray apparently knew how to form complete sentences, but in the interest of expediency, chose not to. It might be that he turned his attention away from people because they did not relate to him, whereas animals would not interrupt or try to finish sentences for him.

Ray became aware of himself physically through the weight loss group. He did lose some weight and was a frequent prize winner as one who lost the most number of pounds between meetings.

Ray's avoidance of people became apparent with the drawings of the "little girl" and his brother, George. When compared with his rendition of a bullmoose or a frog, his knowledge of the human anatomy was sketchy. His fidgety behavior during discussion of human beings or human emotion, especially his own, suggested this was a painful subject for him. The matter was not pursued beyond preliminary probing because of the nature of Ray's therapy. In Ray's case, short-term therapy of an ego-supportive type was designed to be anxiety-suppressive. Transference was encouraged and was, in fact, achieved. This is evidenced by Ray's cooperation with the therapist as early as session two. It was completed but not resolved in session thirteen when Ray questioned the therapist about her absence, then indicated 
that he would stay and participate in the session. Support for Ray's interest in animals was given through gifts of animal pictures. Some social work was employed through the therapist's intervention in writing to and discussion with his counselor regarding bus training.

Agenda planning was done by the therapist and her supervisor but Ray frequently provided the materials for use at some of the sessions. In this way Ray maintained covert control of himself and his environment. Further control was offered to him by suggesting he manipulate the tape recorder when it bothered him. When he told the therapist about his method of dealing with some people by ignoring them, it was clear that he was well aware of his feelings and his surroundings and that he had chosen his own way of coping with that which he found offensive. By session thirteen, client and therapist appeared to be on equal footing when Ray took the initiative and confronted her about her schedule change. Overt control of the next session was handed to the client who chose to go for a walk and to look at fish.

Further recommendations consisted of continued bus training with the participation of Ray's instructor and his mother. 


\section{Discussion}

The trend toward normalization in the field of mental retardation has generated a number of programs designed to integrate retarded citizens into the community. However, individual psychotherapy with retarded adults has been noticeably lacking among these programs. This study was designed to fill that gap by providing one-on-one short-term therapy to members of this population, with primary focus on the process of the therapeutic relationship.

The present study strictly followed the criteria for process research in illustrating the step-by-step method by which the client in therapy moves from a type of impersonal reporting to describing feelings and emotion as part of present experience. The study also followed established guidelines for short-term psychotherapy in terms of time limitations, selection criteria and recommended techniques for the implementation of ego-supportive, anxiety-suppressive therapy. Further, the study showed that retarded adults can benefit from psychotherapy and can move from an impersonal type of experiencing to an expression of feelings in the hereand-now, with feelings owned and accepted.

The important findings of this study in terms of technique and process are delineated as follows:

Transference. Transference was encouraged and actively sought in all of the cases reported here. In establishing 
rapport, the therapist consistently directed discussion around the client's major interest.

With Marian and the new apartment, this discussion resulted in the client's recitation of lists of chores that required attention. The therapist interpreted those recitations as transference from feelings towards an older sister who was directing Marian's life. The therapist shifted the discussion by making unsisterly-like comments about relaxing in an attempt to separate Marian's perception of the two as being alike. The client was soon able to identify the therapist as a resource person and, eventually, as a confidante.

In Richard's case the therapist determined that he needed assurances of privacy and confidentiality and took appropriate steps to insure that his needs were met. There is evidence that the transference was completed (in the sense that the client considered the therapist as a likeable, reliable person) when Richard returned five minutes after the end of a session, encountered the therapist in a hallway, and said "Em'ly? Em-i-ly."

Transference was encouraged in Cathy's case by the therapist's ignoring the possibility that she might be lying and, instead, focusing on her feelings as she reported them. She was also encouraged to share her fantasies. The fantasies gave her, in a sense, permission to make up stories, the outcomes of which could be manipulated to her satisfaction.

The therapist encouraged transference in Ray's case by increasing his self esteem through focusing attention on his 
accomplishments. There was evidence that Ray responded early in therapy by the fact that he furnished his own materials for discussion. He continued to bring items to the sessions throughout the course of therapy.

Resistance. Not many true resistances appeared in the present cases since most of them occurred early in therapy, while true resistances usually occur later in therapy. Marian's hesitance to be genuine stemmed from transference feelings about an older sister. Richard's apprehension was directly related to the size of the room, the tape recorder, and his need for confidentiality. Ray's resistance to therapy appeared throughout as he was continuously agitated over discussions about people. As he explained, however, his slowness and his abbreviated phrases were necessary mechanisms he had developed because not too many people would take the time to lsiten to him finish a sentence if he attempted to use complete and appropriate grammar.

Assertiveness Training. The techniques used in teaching assertiveness skills included an explanation of "I" statements or first-person narrations, and lists of personal rights and freedoms. Role-playing, rehearsing and modeling were also effective in assertiveness training.

Marian benefited considerably from these techniques. She used "I" statements to assist her in becoming a participant in the story she was telling. Discussions concerning "shoulds" and "oughts" of her behavior helped her get in touch 
with her feelings of resentment towards her sister and sorted out her responsibilities to her roommate and friend. In addition, a guided fantasy established her preference for a particular bedroom. The therapist modeled a type of guided fantasy and a rehearsal for a confrontation. Finally, Marian was able to rehearse dialogue she might use to assert herself with her housemate.

Richard asserted himself early in therapy by his insistance on meeting in the larger room. No further training seemed necessary in his case.

Cathy was able to rehearse dialogue she might be able to use in a confrontation with her house parent and with a widowed aunt.

Ray was taught to use "I" statements but chose not to because sentences took too long if they needed to be complete. Other therapeutic techniques employed but not discussed in detail included reflection and clarification of feelings, free association through use of the "Ungame," and reassurance and support.

Learning about feelings. During the therapist's earlier work with retarded adults, it was discovered they seldom had the vocabulary to properly express their feelings. Typical responses to a question such as "What are you feeling?" would be "fine," "okay," "shaky," etc. They could frequently identify "happy," "angry," or "sad," when talking about a picture or story, but almost never used these words in relation to 
themselves. Subtler emotions such as "apprehension," "embarrassment," or "confident" were not in their verbal repertoire. It became the therapist's task to (1) teach clients words to match their feelings and (2) give them permission to express those emotions in the relative safety of the therapeutic environment with the hope that the learning would carry over into their daily lives.

When Marian first came to therapy, she expressed sadness and pride appropriately but had few words to describe those feelings. When she talked about how she felt, she repeated words she had heard from the therapist. As trust grew in the relationship, Marian was able to say that she felt happy or "good." Before the therapy ended, she spontaneously confessed to being upset and was finally able to say that she was really angry.

Richard felt apprehensive about talking in therapy as evidenced by his quiet tone and slow rate of speech. As soon as he had a word to attach to his feeling, he became relaxed and more talkative. He was able to identify the more obvious feelings (mad, hurt, tired, frightened, scared, happy) in pictures and to participate in a discussion of subtler emotions (excited, confident, silly, carefree). About midway through therapy he was able to report that a remark of the therapist pleased him and made him happy. By the end of therapy, Richard had enough access to his feelings to permit himself to blush (with embarrassment) and to laugh out loud. 
However, the feelings remained unverbalized.

Cathy's face was mostly expressionless but she displayed emotion through her voice and body language. As times, both at the beginning and end of therapy, she accepted "bad" news too calmly. Her posture slumped when she was told that a reconciliation with Roger was impossible but she responded by saying that it was okay because they would still be "blood brothers." When the therapist informed her that she had to continue living in the group home she disliked, she said that was okay too, because she already knew the bus route.

At other times, however, Cathy expressed a wide range of appropriate emotion. She was pleased with her birthday party, excited over Christmas, sad at the death of a family member, reverent about being baptized, and angry with her house parent.

Ray denied any emotion except to admit to becoming upset if he were teased or shoved. However, his nervous laugh and fidgeting during the sessions provided evidence that Ray was feeling uncomfortable. The therapist first alleviated his discomfort by terminating the sessions, then by focusing on his behavior until he could regain control.

In assessing movement through the therapeutic process, Marian and Richard made the most progress. They began, essentially, with an impersonal type of reporting and were able to finally experience, and report that experiencing. 
Cathy did not noticeably move through therapy. She appeared to have access to her feelings and expressed them appropriately as her concerns surfaced from session to session but in two critical situations, one at the beginning and one at the end of therapy, her reactions were almost too blase to be authentic.

Ray did not appear to move at all. There was evidence in the transcripts that he was experiencing real emotion but with his noticeable discomfort at being urged to become aware of people, the therapist chose not to pursue that course but focused instead on his positive attributes.

During the course of therapy, however, Cathy was exposed to the technique of reality checking and did learn some assertiveness skills. Ray became aware of his, ability to control his environment and developed an interest in becoming mobile in the community. In conjunction with the weight-loss group, moreover, he was able to lose some weight and become aware of his body.

In sum, this study demonstrated that the process of short-term therapy of the ego-supportive type with retarded adults does result in more verbalization or expression of immediate feelings in some clients, and that all clients benefit in some way from the intimacy of the therapeutic relationship. 
Abel, T. M., \& Kinder, E. F. The subnormal adolescent girl.

In $\mathrm{H}$. Robinson \& $\mathrm{N}$. Robinson, The mentally retarded child. New York: McGraw-Hill, 1976.

Ackerman, N. W., \& Minninger, C. E. Treatment techniques for mental retardation in a school for personality disorders in children. In A. M. Clark \& A. D. B. Clarke (Eds.), Mental deficiency 3rd Ed. New York: Free Press, 1974. Aguilera, D. C., \& Messick, J. M. Crisis intervention. St.

Louis: The C. V. Mosby Company. 1974.

Alexander, F., \& French, T. M. Psychoanalytic therapy. New

York: Ronald Press, 1946.

Barten, H. H. (Ed.). Brief therapies. New York: Behavioral Publications, Inc., 1971.

Baumeister, A. A. (Ed.). Mental retardation. Chicago:

Aldine Publishing Company, 1967.

Bellak, L., \& Small, I. Emergency and brief psychotherapy.

New York: Grune and Stratton, 1965.

Bialer, I. Psychotherapy and other adjustment techniques with the mentally retarded. In A. A. Baumeister (Ed.), Mental retardation: appraisal, education, and rehabilitation. Chicago: Aldine, 1967.

Bugental, J.F. T. Search for existential identity: patienttherapist dialogues in humanistic psychotherapy. San Francisco: Jossey-Bass Publishers, 1976. Bugental, J. F. T. Psychotherapy and process: the fundamentals of an existential-humanistic approach. Reading; Mass.: Addison-Wesley, 1978. 
Burton, A. Psychotherapy with the mentally retarded. American Journal of Mental Deficiency, 1954, 58, 486-489.

Chaplin, J. P. Dictionary of psychology. New York: Dell Publishing Co., Inc., 1975.

Chidester, L., \& Menninger, K. A. The application of psychoanalytic methods to the study of mental retardation. In A. M. Clarke \& A. D. B. Clarke (Eds.), Mental deficiency 3rd Ed. New York: Free Press, 1974.

Clarke, A. M., \& Clarke, A. D. B. (Eds.). Mental deficiency 3rd Ed. New York: Free Press, 1974.

Edwards, J. Personal interview. Portland State University, Department of Special Education, 1978.

Ellis, N. R. (Ed.). International review of research in mental retardation (Vol. 2). New York: Academic Press, 1966 .

Fine, R. Psychoanalysis. In R. Corsini (Ed.), Current psychotherapies. Itasca, Ill.: F. E. Peacock Publishers, 1973.

Fenichel, O. Brief psychotherapy. In H. Fenichel \& D. Rapaport (Eds.), The collected papers of Otto Fenichel. New York: Norton, 1954.

Gardner, W. I. What should be the psychologist's role? Mental Retardation, 1967, $5,29-31$. Gottschalk, L. A. \& Auerbach, A. H. Methods of research in psychotherapy. New York: Appleton-Century-Crofts, 1966. Grossman, H. (Ed.). Manual on terminology and classification in mental retardation, 1973 revision. Washington, D. C.: American Association of Mental Deficiency, 1973. 
Gunzberg, H. C. Psychotherapy. In A. M. Clarke \& A. D. B. Clarke (Eds.), Mental deficiency 3rd Ed. New York: Free Press, 1975

Halpern, A. S. Why not psychotherapy? Mental Retardation, 1968 , Vol. 6, No. 6, 48-50.

Halpern, A. S., \& Berard, W. R. Counseling for the mentally retarded: A review for practice. In P. Browning (Ed.), Mental retardation: Rehabilitation and counseling.

Springfield, Ill.: Charles C. Thomas, 1974.

Kiesler, D. J. The process of psychotherapy: empirical

foundations and systems of analysis. Chicago: Aldine 1973

Klopfer, W. J. Personal interview. Portland State University, Department of Psychology, 1979.

Leland, H., \& Smith, D. E. Mental retardation: present and future perspectives. Worthington: Charles A. Jones, 1974 . Lott, G. Psychotherapy of the mentally retarded: values and cautions. In F. J. Menolascino, Psychiatric approaches to mental retardation. New York: Basic Books, 1970. Malan, D. H. A study of brief psychotherapy. London: Tavistock Publications, 1963.

Masserman, J. H. Historical-comparative and experimental roots of short-term therapy. In I. R. Wolberg (Ed.), Short-term psychotherapy. New York: Grune \& stratton, 1965.

Meador, B. D. \& Rogers, C. R. Client-centered therapy. In R. Corsini (Ed.), Current psychotherapies. Itasca, Ill.: Peacock Publishers, 1973. 
Neham, S. Psychotherapy in relation to mental deficiency. American Journal of Mental Deficiency, 1951, 55, 557-572. Prehm, H. J. Mental retardation: definition, classification and prevalence. In P. Browning (Ed.), Mental retardation: rehabilitation and counseling. Springfield, Ill.: Charles C. Thomas, 1974 . Robinson, H. B. \& Robinson, N. M. The mentally retarded Child. New York: McGraw-Hill, 1976. Rogers, C. R. A tentative scale for the measurement of process in psychotherapy. In E. A. Rubinstein \& M. B. Parloff (Eds.), Research in psychotherapy. Washington, D. C.: American Psychological Association, 1959. Rogers, C. R. (Ed.). The therapeutic relationship and its impact: a study of psychotherapy with schizophrenics. Madison, Wisc.: The University of Wisconsin Press, 1967. Rogers, C. R. \& Rablen, R. A. A scale of process in psychotherapy. Unpublished manuscript. In M. H. Klein, P. L. Mathieu, E. T. Gendlin, \& D. J. Kiesler, The experiencing scale. Madison, Wisc.: Wisconsin Psychiatric Institute, 1969 .

Selwa, B. I. Preliminary considerations in psychotherapy with retarded children. Journal of School Psychology, 1971, Vol. 9, No. 1, 12-15. Sifneos, P. E. Two different kinds of psychotherapy of short duration. In H. H. Barten (Ed.), Brief therapies. New York: Behavioral Publications, Inc., 1971. Sifneos, P. E. Short-term psychotherapy and emotional crisis. Cambridge: Harvard University Press, 1972. 
Snyder, w. W. Casebook of non-directive counseling. Cam-

bridge: The Riverside Press, 1947.

Stacey, C. I. \& DeMartino, M. F. Counseling and psycho-

therapy with the mentally retarded: A book of readings.

Glencoe, III.: The Free Press, 1957.

Sternlicht, M. Psychotherapeutic procedures with the retard-

ed. In N. R. Ellis (Ed.), International review of research in mental retardation (Vol. 2). New York: Academic Press, 1966 .

Strachey, J. The standard edition of the complete psychological works of Sigmund Freud (Vol. XXIV). London: The Hogarth Press, 1974.

Strachey, J. The standard edition of the complete psychological works of Sigmund Freud (Vol. XVII). London: The Hogarth Press, 1974.

Straker, M. A review of short-term psychotherapy. Diseases of the Nervous System, October 1977, 813-816. Szurek, S. A. \& Philips, I. Mental retardation and psychotherapy. In I. Philips (Ed.), Prevention and treatment of mental retardation. New York: Basic Books, 1966. Thorne, F. C. Counseling and psychotherapy with mental defectives. American Journal of Mental Deficiency, 52, 1948, 263-271.

Wall, P. B. The relationship of weight loss to self concept in the mentally retarded adult. Unpublished thesis, Portland State University, 1978.

Watson, R. I. A brief history of clinical psychology. Psychological Bulletin, 1953, 50, 321-346. 
Weiner, I. B. Clinical methods in psychology. New York: John Wiley \& Sons, Inc., 1976.

Weist, G. Psychotherapy with the mentally retarded. American Journal of Mental Deficiency, 1955, 59, 640-644.

Wolfensberger, $W$. The origin and nature of our institutional models. Syracuse: Human Policy Press, 1975. woody, R. H. \& Billy, J. J. Counseling and psychotherapy for the mentally retarded: A survey of opinions and practices. Mental Retardation, 1966, $4,20-23$. 